\title{
EVOLUTIONARY GAME ANALYSIS FOR RENT-SEEKING BEHAVIOR SUPERVISION OF MAJOR INFRASTRUCTURE PROJECTS BASED ON PROSPECT THEORY
}

\author{
Lelin $\mathrm{LV}^{1}$, Huimin $\mathrm{LI}^{2 *}$, Zhuofu WANG ${ }^{1}$, Chengyi ZHANG ${ }^{3}$, Ran QIAO1 \\ ${ }^{1}$ Business School, Hohai University, Nanjing, China \\ ${ }^{2}$ Department of Construction Engineering and Management, North China University of Water Resources \\ and Electric Power, Zhengzhou, China \\ ${ }^{3}$ Department of Civil and Architectural Engineering, University of Wyoming, Laramie, USA
}

Received 8 June 2021; accepted 24 September 2021; first published online 31 December 2021

\begin{abstract}
Major infrastructure projects (MIPs) possess significant strategic positions in the national economy and social development. However, recently, the rent-seeking behavior between supervision units and project contractors has intensified in project construction. This paper aims to study the behavior decision-making of stakeholders in rent-seeking behavior supervision system of MIPs. In the complex and uncertain environment of MIPs, game players have cognitive bias and value perception preference. Therefore, this study introduced prospect theory and constructed the perceived return matrix and evolutionary game model of MIP rent-seeking behavior supervision among project owners, supervision units, and project contractors. From the perspective of risk perception theory, the reasons for the behavioral tendencies of game participants and the conditions for the steady state of strategy selection were explored through system dynamics simulations. The results showed that the stable state of the optimal strategy in the rent-seeking behavior supervision system of MIPs is related to the cognitive bias of the game players and is influenced by the level of regulation cost, the intensity of punishment and the size of accident losses. The contribution of this study lies in providing theoretical basis and decision support for constructing a long-term preventive mechanism for rent-seeking activities in MIPs.
\end{abstract}

Keywords: major infrastructure projects, rent-seeking behavior, evolutionary game analysis, prospect theory, supervision mechanism.

\section{Introduction}

Major infrastructure projects (MIPs) are large-scale engineering facilities that provide basic public services for social production and economic development and people's lives (Liu et al., 2018; Flyvbjerg, 2014; Flyvbjerg \& Turner, 2018). A range of MIPs has been built and operated, such as the South-to-North Water Diversion Project, Hong Kong-ZhuhaiMacao Bridge, and Qinghai-Tibet Railway (Ma et al., 2020; Zhao et al., 2017). However, it cannot be ignored that a series of quality accidents about MIPs have widely triggered severe social concerns recently (Zhang et al., 2018; Kim et al., 2013). For example, the collapse of a cooling tower construction platform during the third phase expansion project of Fengcheng Power Plant in Jiangxi province caused a direct economic loss of 101 million yuan (Zhang et al., 2020). The increasingly prominent quality issues and frequent accidents have gradually revealed the regulatory deficiencies of MIPs.

The project owner, the supervision unit, and the project contractor are the most important stakeholders in the MIPs. The decision and interaction for transaction behavior of all parties will have a significant impact on the projects (AsilianMahabadi et al., 2018; Mei et al., 2017; Yuan, 2017; Li et al., 2013). Due to the information asymmetry among stakeholders, the project contractor usually masters more about the project environment and actual working conditions than the project owner. It is difficult for the project owner to observe the construction behavior of the project contractor directly. Therefore, the project contractor may make use of this advantage to conduct opportunistic behavior that is harmful to the interests of the project owner (Wen et al., 2014; Chen et al., 2014; Feng et al., 2019). In addition, the supervision unit may reduce the quality of supervision work, or seek rent from the project contractor with its supervision and acceptance

*Corresponding author. E-mail: lihuimin3646@163.com 
rights to maximize its own interests (Chen et al., 2016; Wen et al., 2014). Namely, the supervision unit and the project contractor engage in rent-seeking activities/collusion behaviors. Therefore, the information asymmetry is the precondition of the supervision unit and the project contractor of collusion to be implemented. The pursuit of interests is the spontaneous motivation that triggers the supervision unit and the project contractor to collude (Liu et al., 2020).

Due to the information asymmetry and the inconsistency of interest objectives among stakeholders, it is inevitable to occur rent-seeking behavior in project construction, making the project face many safety quality potentials (Wang et al., 2014). The interaction between the behaviors of project transaction participants is a mutual game process under bounded rationality and uncertainty, which belongs to a finite repeated game and meets the conditions of the evolutionary game (Liu et al., 2021; Gong et al., 2021). Therefore, more scholars have used evolutionary game theory to explore rent-seeking behaviors between project agents. Xu et al. (2020) constructed a tripartite evolutionary game model among the government, soil-polluting companies, and third-party governance companies. They analyzed the interaction mechanism of each agent's strategy choice and the evolution of each agent's strategy choice under different parameter trends. Considering the existence of rent-seeking behavior, Liu et al. (2020) constructed an evolutionary game model among the state administration of work safety, local regulatory departments of work safety and mining enterprises. The results showed that the possibility of rent-seeking could be reduced by increasing the severity of punishment on illegal mining enterprises. To sum up, evolutionary game theory provides methods and ideas for studying the formation mechanism of rent-seeking behavior in supervision and how to establish effective supervision and prevention mechanism for rent-seeking behavior in MIPs (Xin, 2019). Therefore, the evolutionary game method can be used to explore better the transaction participants' strategy formation and evolution process in the safety supervision system of MIPs.

These literatures provide ideas for exploring in-depth the rent-seeking behavior of MIPs. However, the influence of psychological factors on the decision-making process of subjects was not considered. The decision-making preference behaviors of game subjects under the condition of engineering complexity cannot be fully explained. MIPs are characterized by significant complexity and bounded rationality of multiple subjects, making transaction subjects have subjective judgment bias and value perception preference when facing the complex and uncertain decision-making environment. The prospect theory proposed by Kahneman and Tversky (1979) can better explain the gain and loss preferences of transaction subjects, and describe the judgment and decision-making behavior under the uncertainty condition, so it applies to the analysis for the decision-making behavior of transaction subjects under the complexity and uncertainty of MIPs. Accordingly, to bridge these research gaps, this paper introduces the prospect theory to construct the tripartite perceived payoff matrix and evolutionary game model for rent-seeking behavior supervision of MIPs with considering the loss avoidance and cognitive bias of game players.

The main contributions of this study as follows: First, based on the evolutionary game theory, this study introduced the prospect theory to modify the parameters of the traditional payment matrix, and constructed a tripartite evolutionary game model for rent-seeking behavior supervision of MIPs. Second, through the analysis of tripartite equilibrium game, this study deeply explored the long-term equilibrium characteristics of typical evolution game scenarios of unilateral stability strategy and mixed stability strategy. From the perspectives of cognitive bias and risk preference, the behavior evolution and stable conditions for rent-seeking behavior supervision mechanism of MIPs were discussed. Finally, the system dynamic model simulated the influence of different parameter on the strategy selection and behavior evolution results of game players, and revealed the dynamic evolution mechanism for behavior decision-making of different subjects in the rent-seeking behavior supervision process. The driving factors, changing conditions, and stable results of strategies selection in the tripartite game provide theoretical basis and decision support for the long-term prevention mechanism of rent-seeking activities.

The remainder of the paper is organized as follows. In Section 1, the problem description and basic assumptions are elaborated. Section 2 constructs and solves the evolutionary game model for rent-seeking behavior supervision of MIPs based on the prospect theory. Section 3 focuses on the tripartite game equilibrium analysis, including the unilateral stability strategy and the mixed stability strategy of the game players. In Section 4, the system dynamics simulation analysis for the evolutionary model for rent-seeking behavior supervision of MIPs is presented. Finally, Section 5 draws a discussion. Conclusion is presented at the end.

\section{Model assumptions}

\subsection{Problem description}

MIPs are generally invested by the government or jointly invested by the government and private sector in China. The quality and safety supervision of MIPs involves multiple interest subjects, among which, the project owner represents the public interest of the society and bears significant regulatory responsibilities. In order to ensure the quality and safety of MIPs, the project owner often establish a project department to supervise the construction of MIPs. The supervision unit is entrusted by the project owner to carry out overall supervision of the project and is indispensable in project supervision. The supervision unit has the rights to supervise the project contractor, and the supervision and acceptance rights is 
granted by the project owner. The project contractor, as the implementer of the project, is the first responsible subject for implementing the quality and safety work of the project. There are dynamic game relationships among the three subjects, which jointly affect the quality and safety of MIPs. The principal-agent relationships among the project owner, supervision unit and project contractor of MIPs is shown in Figure 1. From the perspective of economics, this paper discusses the reasons and conditions of rent-seeking behavior in the construction supervision process of MIPs.

First, the asymmetry of information. Information asymmetry exists in the principal-agent relationships among the project owner, supervision unit, and project contractor, which provides conditions for rent-seeking activities. Specifically, the behavior strategy of the supervision unit is not controlled by the project owner, and it is difficult for the project owner to directly observe the construction behavior of the project contractor. This is the root cause of the rent-seeking problem.

Second, the existence of privilege. The supervision unit has the supervision and acceptance rights of the project contractor. According to the rent-seeking theory, rent-seeking behavior is a non-productive activity that takes advantage of the special right (Aidt, 2016; He \& Shan, 2021). The supervision unit may use the privilege of improper interference with the project contractor in the project transaction process. Therefore, it is a prerequisite for rent-seeking activities that the supervision unit has the right to supervise and manage the project.

Third, the attribute of economic man. According to the Hypothesis of Economic Man, driven by the pursuit of selfinterest maximization, the supervision unit has the possibility of cheating in work and rent-seeking activities (Xu et al., 2020). It is assumed that the supervision unit conducts negative supervision on the quality, safety, and environment of MIPs. In that case, the project contractor may reduce the construction cost, obtain an undue time limit or excessive cost claims (Cao \& Zhou, 2021). Both the supervision unit and the project contractor will realize that they can get additional benefits through rent-seeking activities.

The existence of rent-seeking renders supervision a mere formality, because supervision unit may conceal or ignore accident potential in projects, increasing the likelihood of accidents and leading to the waste of resources and the deterioration of social atmosphere (He \& Shan, 2021; Ibarrondo-Davila et al., 2015). Due to the more significant uncertainty of MIPs, rent-seeking behavior is more likely to occur than general projects, with more serious consequences. Therefore, it is of great significance to explore the rent-seeking behavior supervision mechanism of MIPs (Figure 1).

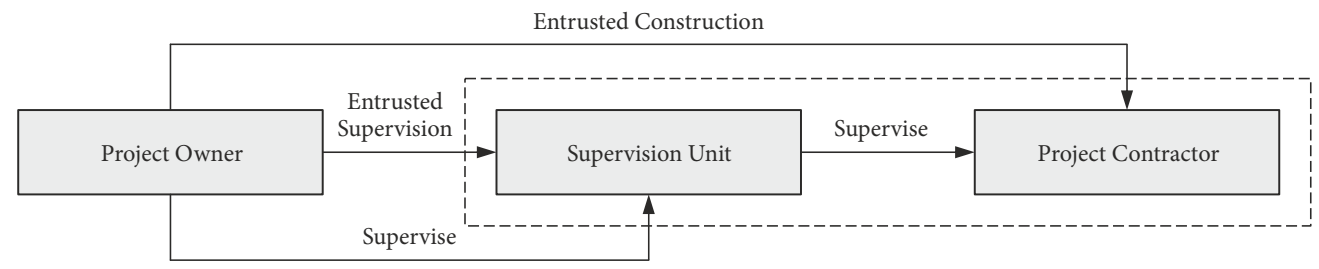

Figure 1. Supervision relationship of tripartite game players of MIPs

\subsection{Basic assumptions}

Assumption 1: In the rent-seeking behavior supervision mechanism of MIPs, due to incomplete and asymmetrical information, it is assumed that each player in the game has only limited rationality.

Assumption 2: The classical expected utility theory ignores the influence of psychological perception factors on the decision-making process of game players. On this basis, Kahneman and Tversky (1979) put forward the prospect theory in view of the inconsistency of decision makers' risk preference in the face of gains and losses. The expected total utility of the decision depends on the value function and the weight function, and the prospect utility function can be expressed as:

$$
V(p, x)=\sum_{i=1}^{n} \mathrm{v}\left(x_{i}\right) \pi\left(p_{i}\right),
$$

here, $V(p, x)$ is the prospect utility function. $v\left(x_{i}\right)$ is the value function. $\pi\left(p_{i}\right)$ is the weight function.

Assumption 3: Prospect theory holds that people's perception of loss and gain is the difference between the actual value of loss and gain and the reference point (Liu et al., 2011; Trepel et al., 2005). Specifically, for income-type results above the reference point, individuals tend to risk aversion. For loss-type results below the reference point, individuals tend to risk preference. Therefore, the value function can be expressed as:

$$
v\left(x_{i}\right)=\left\{\begin{array}{l}
\left(x_{i}-R\right)^{\alpha}, x_{i} \geq R \\
-\lambda\left(R-x_{i}\right)^{\beta}, x_{i}<R
\end{array},\right.
$$

here, $x_{i}$ is the actual gains and losses. $R$ represents the reference point. $\alpha$ and $\beta$ are risk preference coefficients $(0 \leq \alpha, \beta \leq 1)$. $\lambda$ is the loss avoidance coefficient, $\lambda \geq 1$.

Assumption 4: The decision weight function is also called subjective probability. The weight function can be expressed as: 


$$
\pi\left(p_{i}\right)=\frac{p_{i}^{\gamma}}{\left[p_{i}^{\gamma}+\left(1-p_{i}\right)^{\gamma}\right]^{1 / \gamma}},
$$

here, $p_{i}$ is the objective probability for the occurrence of event $i$. Particularly, $\pi(0)=0, \pi(1)=1$. The smaller $\gamma$ is, the more curved it is, and $0 \leq \gamma \leq 1$. Low probability events are typically overestimated, and high probability events are usually underestimated in prospect theory. When $p_{i}$ is very small, $\pi\left(p_{i}\right)>p_{i}$ will be obtained. Similarly, when $p_{i}$ is very big, $\pi\left(p_{i}\right)<p_{i}$ will be obtained.

Assumption 5: It is assumed that every game player has two strategies to choose from. The strategy set of project owner is \{strict regulation, loose regulation\}, and the probability is $p_{1}\left(0 \leq p_{1} \leq 1\right)$ and $1-p_{1}$, respectively. The strategy set of supervision unit is $\left\{\right.$ rejecting rent-seeking, accepting rent-seeking\}, and the probability is $p_{2}\left(0 \leq p_{2} \leq 1\right)$ and $1-p_{2}$, respectively. The strategy set of project contractor is \{rejecting rent-seeking, accepting rent-seeking\}, and the probability is $p_{3}\left(0 \leq p_{3} \leq 1\right)$ and $1-p_{3}$, respectively.

\section{Evolutionary game model for rent-seeking behavior supervision}

\subsection{Model construction}

According to the profit-maximization principle, game players make the most beneficial decision based on their perception of strategic value. However, game players possess perceived utility only when they are uncertain about costs and benefits, and there is no difference between the perceived value and actual utility of the loss and benefit determined by decisionmakers (Shen et al., 2018). In the supervision mechanism of MIPs, the supervision cost and service fee are deterministic expenditure, which adopts the actual value. The remaining parameters are related to the subjective feelings of the game players and are expressed as prospect values. This study summarizes the variables and parameters used to build the perceived payoff matrix as shown in Table 1 . Values for these variables and parameters are usually available from actual project implementation. For example, the variable $C_{s r}$ is the cost of human, material, and financial resources that the project owner needs to invest when adopting strict regulation strategy, which are available in the cost accounting table of the project owner; the parameter $\delta$ can be obtained by estimation from past experience and cases. Based on the above basic assumptions and the variables and parameters in Table 1, this paper constructs a three-party payoff matrix of the project owner, supervision unit, and project contractor. The perceived payoff matrix is shown in Table 2.

Table 1. The meaning of the variables and parameters in the perceived payoff matrix

\begin{tabular}{|c|l|}
\hline Symbols & \multicolumn{1}{|c|}{ Description } \\
\hline $\mathrm{C}_{s r}$ & Regulation cost of strict regulation strategy adopted by the project owner. \\
\hline$C_{l r}$ & Regulation cost of loose regulation strategy adopted by the project owner. \\
\hline$R_{l p}$ & The social benefit that the project owner will get when the project contractor conducts normative construction. \\
\hline$P_{g o}$ & The punishment imposed on it by the superior government when project owner adopts loose regulation. \\
\hline$C_{r s}$ & Regulation cost of refusing the rent-seeking behavior strategy adopted by the supervision unit. \\
\hline$C_{a s}$ & Regulation cost of accepting the rent-seeking behavior strategy adopted by the supervision unit. \\
\hline$M$ & Service fee paid by the project owner to the supervision unit. \\
\hline$B$ & $\begin{array}{l}\text { Rent-seeking income of accepting the rent-seeking behavior strategy adopted by the supervision unit or rent-seeking } \\
\text { cost of conducting non-normative construction strategy adopted by the project contractor. }\end{array}$ \\
\hline$C_{s c}$ & Regulation cost of conducting normative construction strategy adopted by the project contractor. \\
\hline$C_{n s}$ & Regulation cost of conducting non-normative construction strategy adopted by the project contractor. \\
\hline$N$ & Payoff obtained by the project contractor from the project owner. \\
\hline$L_{l c}$ & $\begin{array}{l}\text { The loss caused by an accident to the project owner when the project contractor conducts non-normative } \\
\text { construction. }\end{array}$ \\
\hline$L_{l o}$ & The loss caused by an accident to the project contractor when non-normative construction is carried out. \\
\hline$\delta$ & The probability of the accident. \\
\hline$\psi$ & The discount coefficient of loss. \\
\hline$F_{s}$ & The penalty amount imposed by the project owner on the supervision unit. \\
\hline$F_{c}$ & The penalty amount imposed by the project owner on the project contractor. \\
\hline
\end{tabular}


Table 2. The perceived payoff matrix for supervision mechanism of MIPs

\begin{tabular}{|c|c|c|}
\hline \multicolumn{3}{|c|}{ Project owner Selects Strict Regulation Strategy $\left(p_{1}\right)$} \\
\hline & $\begin{array}{l}\text { Supervision unit rejects } \\
\text { rent-seeking }\left(p_{2}\right)\end{array}$ & $\begin{array}{l}\text { Supervision unit accepts } \\
\text { rent-seeking }\left(1-p_{2}\right)\end{array}$ \\
\hline \multirow{3}{*}{$\begin{array}{l}\text { Project contractor } \\
\text { conducts normative } \\
\text { construction }\left(p_{3}\right)\end{array}$} & $-C_{s r}-M-N+V\left(R_{l p}\right)$ & $-C_{s r}-M-N+V\left(R_{l p}\right)+V\left(F_{s}\right)$ \\
\hline & $-C_{r s}+M$ & $-C_{a s}+M+V\left(-F_{s}\right)$ \\
\hline & $-C_{s c}+N$ & $-C_{s c}+N$ \\
\hline \multirow{3}{*}{$\begin{array}{l}\text { Project contractor conducts } \\
\text { non-normative construction } \\
\left(1-p_{3}\right)\end{array}$} & $-C_{s r}-M-N+V\left(F_{c}\right)+V\left(-\delta \psi L_{l o}\right)$ & $-C_{s r}-M-N+V\left(F_{c}\right)+V\left(F_{s}\right)+V\left(-\delta \psi L_{l o}\right)$ \\
\hline & $-C_{r s}+M$ & $-C_{a s}+M+V(B)+V\left(-F_{s}\right)$ \\
\hline & $-C_{n s}+N+V\left(-F_{c}\right)+V\left(-\delta \psi L_{l c}\right)$ & $-C_{n s}+N+V(-B)+V\left(-F_{c}\right)+V\left(-\delta \psi L_{l c}\right)$ \\
\hline \multicolumn{3}{|c|}{ Project owner Selects Loose Regulation Strategy $\left(1-p_{1}\right)$} \\
\hline & $\begin{array}{l}\text { Supervision unit rejects } \\
\text { rent-seeking }\left(p_{2}\right)\end{array}$ & $\begin{array}{l}\text { Supervision unit accepts } \\
\text { rent-seeking }\left(1-p_{2}\right)\end{array}$ \\
\hline \multirow{3}{*}{$\begin{array}{l}\text { Project contractor } \\
\text { conducts normative } \\
\text { construction }\left(p_{3}\right)\end{array}$} & $-C_{l r}-M-N+V\left(R_{l p}\right)+V\left(-P_{g o}\right)$ & $-C_{l r}-M-N+V\left(R_{l p}\right)+V\left(-P_{g o}\right)$ \\
\hline & $-C_{r s}+M$ & $-C_{a s}+M$ \\
\hline & $-C_{s c}+N$ & $-C_{s c}+N$ \\
\hline \multirow{3}{*}{$\begin{array}{l}\text { Project contractor conducts } \\
\text { non-normative construction } \\
\left(1-p_{3}\right)\end{array}$} & $-C_{l r}-M-N+V\left(F_{c}\right)+V\left(-\delta \psi L_{l o}\right)+V\left(-P_{g o}\right)$ & $-C_{l r}-M-N+V\left(-\delta L_{l o}\right)+V\left(-P_{g o}\right)$ \\
\hline & $-C_{r s}+M$ & $-C_{a s}+M+V(B)$ \\
\hline & $-C_{n s}+N+V\left(-F_{c}\right)+V\left(-\delta \psi L_{l c}\right)$ & $-C_{n s}+N+V(-B)$ \\
\hline
\end{tabular}

\subsection{Model solution}

According to the basic assumptions and the perceived payoff matrix of MIPs based on prospect theory, the probability of the project owner selecting strict regulation strategy is $p_{1}$ and the probability of choosing loose regulation strategy is $1-p_{1}$. The expected prospect values of two strategies of project owner supervision are denoted by $E_{p_{1}}$ and $E_{1-p_{1}}$, respectively, and the average prospect value is symbolized as $\bar{E}_{p_{1}}$.

$$
\begin{aligned}
& E_{p_{1}}=p_{2} p_{3}\left[-C_{s r}-M-N+V\left(R_{l p}\right)\right]+\left(1-p_{2}\right) p_{3}\left[-C_{s r}-M-N+V\left(R_{l p}\right)+V\left(F_{s}\right)\right]+ \\
& p_{2}\left(1-p_{3}\right)\left[-C_{s r}-M-N+V\left(F_{c}\right)+V\left(-\delta \psi L_{l o}\right)\right]+\left(1-p_{2}\right)\left(1-p_{3}\right)\left[-C_{s r}-M-N+V\left(F_{c}\right)+V\left(F_{s}\right)+V\left(-\delta \psi L_{l o}\right)\right] \\
& E_{1-p_{1}}=p_{2} p_{3}\left[-C_{l r}-M-N+V\left(R_{l p}\right)+V\left(-P_{g o}\right)\right]+\left(1-p_{2}\right) p_{3}\left[-C_{l r}-M-N+V\left(R_{l p}\right)+V\left(-P_{g o}\right)\right]+ \\
& p_{2}\left(1-p_{3}\right)\left[-C_{l r}-M-N+V\left(F_{c}\right)+V\left(-\delta \psi L_{l o}\right)+V\left(-P_{g o}\right)\right]+\left(1-p_{2}\right)\left(1-p_{3}\right)\left[-C_{l r}-M-N+V\left(-\delta L_{l o}\right)+V\left(-P_{g o}\right)\right] ; \\
& \bar{E}_{p_{1}}=p_{1} E_{p_{1}}+\left(1-p_{1}\right) E_{1-p_{1}} .
\end{aligned}
$$

According to the perceived payoff matrix, the expected prospect values of two strategies of supervision unit are denoted by $E_{p_{2}}$ and $E_{1-p_{2}}$, respectively, and the average prospect value is symbolized as $\bar{E}_{p_{2}}$. Then, the $E_{p_{2}}$, $E_{1-p_{2}}$, and $\bar{E}_{p_{2}}$ can be obtained.

$$
\begin{aligned}
& E_{p_{2}}=p_{1} p_{3}\left[-C_{r s}+M\right]+\left(1-p_{1}\right) p_{3}\left[-C_{r s}+M\right]+p_{1}\left(1-p_{3}\right)\left[-C_{r s}+M\right]+\left(1-p_{1}\right)\left(1-p_{3}\right)\left[-C_{r s}+M\right] \\
& E_{1-p_{2}}=p_{1} p_{3}\left[-C_{a s}+M+V\left(-F_{s}\right)\right]+\left(1-p_{1}\right) p_{3}\left[-C_{a s}+M\right]+p_{1}\left(1-p_{3}\right)\left[-C_{a s}+M+V(B)+V\left(-F_{s}\right)\right]+ \\
& \left(1-p_{1}\right)\left(1-p_{3}\right)\left[-C_{a s}+M+V(B)\right] \\
& \bar{E}_{p_{2}}=p_{2} E_{p_{2}}+\left(1-p_{2}\right) E_{1-p_{2}}
\end{aligned}
$$


Similarly, the expected prospect values $\left(E_{p_{3}}, E_{1-p_{3}}\right)$ of two strategies of project owner supervision, and the average prospect value $\bar{E}_{p_{3}}$ are calculated as follows:

$$
\begin{aligned}
& E_{p_{3}}=p_{1} p_{2}\left[-C_{s c}+N\right]+\left(1-p_{1}\right) p_{2}\left[-C_{s c}+N\right]+p_{1}\left(1-p_{2}\right)\left[-C_{s c}+N\right]+\left(1-p_{1}\right)\left(1-p_{2}\right)\left[-C_{s c}+N\right] ; \\
& E_{1-p_{3}}=p_{1} p_{2}\left[-C_{n s}+N+V\left(-F_{c}\right)+V\left(-\delta \psi L_{l c}\right)\right]+\left(1-p_{1}\right) p_{2}\left[-C_{n s}+N+V\left(-F_{c}\right)+V\left(-\delta \psi L_{l c}\right)\right]+ \\
& p_{1}\left(1-p_{2}\right)\left[-C_{n s}+N+V(-B)+V\left(-F_{c}\right)+V\left(-\delta \psi L_{l c}\right)\right]+\left(1-p_{1}\right)\left(1-p_{2}\right)\left[-C_{n s}+N+V(-B)\right] ; \\
& \bar{E}_{p_{3}}=p_{3} E_{p_{3}}+\left(1-p_{3}\right) E_{1-p_{3}} .
\end{aligned}
$$

Prospect theory can effectively describe the cognition and decision-making of the game players of boundedly rational behavior under uncertain circumstances (Barberis, 2013). According to Assumptions, each game player's profit and loss prospect value can be obtained. When the supervision unit's probability of accepting the rent-seeking behavior strategy is 1 , the punishment imposed by the project owner is $F_{s}$. Accordingly, the project owner receives income $F_{s}$. When the supervision unit chooses the strategy of refusing rent-seeking behavior, the project owner will punish it with 0 . Accordingly, the project owner will not get the income. Therefore, the prospect value of $F_{s}$ is expressed as follows:

$$
\begin{aligned}
& V\left(F_{s}\right)=\pi(1) \cup\left(F_{s}\right)+\pi(0) \cup(0)=F_{s}{ }^{\alpha} ; \\
& V\left(-F_{s}\right)=\pi(1) \cup\left(-F_{s}\right)+\pi(0) \cup(0)=-\lambda F_{s}{ }^{3} .
\end{aligned}
$$

Similarly, the prospect value of $F_{c}$ can be obtained:

$$
\begin{aligned}
& V\left(F_{c}\right)=\pi(1) \cup\left(F_{c}\right)+\pi(0) \cup(0)=F_{c}^{\alpha} ; \\
& V\left(-F_{c}\right)=\pi(1) \cup\left(-F_{c}\right)+\pi(0) \cup(0)=-\lambda F_{c}{ }^{\beta} .
\end{aligned}
$$

When the probability of the project contractor choosing a normative construction strategy is 1 , the social benefit obtained by the project owner is $R_{l p}$. When the project contractor adopts the opposite strategy, the social benefit obtained by the project owner is 0 , then the prospect value of $R_{l p}$ is calculated as follows:

$$
V\left(R_{l p}\right)=\pi(1) \cup\left(R_{l p}\right)+\pi(0) \cup(0)=R_{l p}^{\alpha} .
$$

Similarly, the prospect value of $B, L_{l o}$, and $L_{l c}$ can be obtained as follows:

$$
\begin{aligned}
& V(B)=\pi(1) \cup(B)=B^{\alpha}, V(-B)=\pi(1) \cup(-B)=-\lambda B^{\beta}, V\left(-P_{g o}\right)=\pi(1) \cup\left(-P_{g o}\right)=-\lambda P_{g o}^{\beta} ; \\
& V\left(-\delta \psi L_{l o}\right)=\pi(1) \cup\left(-\delta \psi L_{l o}\right)=-\lambda \delta \psi L_{l o}{ }^{\beta}, V\left(-\delta L_{l o}\right)=-\lambda \delta L_{l o}{ }^{\beta}, V\left(-\delta \psi L_{l c}\right)=-\lambda \delta \psi L_{l c}{ }^{\beta} .
\end{aligned}
$$

\section{Tripartite game equilibrium analysis}

Evolutionary game theory originated from biology and is the product of that survival of the fittest concept in biology and game theory in economics (Chen et al., 2015). Compared with traditional game theory, evolutionary game breaks through the restriction of complete rationality of traditional game theory (Lai \& Li, 2013). The asymptotic stability investigation is reflected in a deterministic evolutionary game, in which the group game strategy is determined by the properties of an individual, so that the dominant strategy will be spread throughout the population due to a high payoff of it (Cheng \& Yu, 2018). Replicator dynamics is a mechanism to describe the dynamic strategy adjustment of players with limited rationality who can simply imitate the dominant strategy. When the evolution of individual strategy occurs in the space, the partial differential equations are usually used to describe the replicator dynamics model. the replicator dynamics equation has superior mathematical properties for solving the equilibrium strategy of a deterministic evolutionary game (Cheng \& Yu, 2018). Therefore, based on the bounded rationality of the project owner, supervision unit, and project contractor of MIP, this study analyzes the learning and adjustment process of strategy selection of the three parties by using the replicator dynamics mechanism.

\subsection{The unilateral stability strategy of the game players}

\subsubsection{The evolutionary stability strategies of project owner}

According to the prospect values obtained, the expected prospect value of the strict regulation and loose regulation strategies of the project owner can be obtained as follows:

$$
E_{p_{1}}=p_{2}\left(-F_{s}^{\alpha}\right)+p_{3}\left(R_{l p}^{\alpha}-F_{c}^{\alpha}+\lambda \delta \psi L_{l o}{ }^{\beta}\right)+\left(-C_{s r}-M-N+F_{c}^{\alpha}+F_{s}^{\alpha}-\lambda \delta \psi L_{l o}{ }^{\beta}\right) ;
$$


$E_{1-p_{1}}=p_{2} p_{3}\left(-F_{c}^{\alpha}+\lambda \delta \psi L_{l o}^{\beta}-\lambda \delta L_{l o}^{\beta}\right)+p_{2}\left(F_{c}^{\alpha}-\lambda \delta \psi L_{l o}^{\beta}+\lambda \delta L_{l o}^{\beta}\right)+p_{3}\left(R_{l p}^{\alpha}+\lambda \delta L_{l o}{ }^{\beta}\right)+\left(-C_{l r}-M-N-\lambda \delta L_{l o}{ }^{\beta}-\lambda P_{g o}{ }^{\beta}\right)$.

According to Eqns (18)-(19), the dynamic replication equation $F\left(p_{1}\right)$ of the project owner can be obtained as follows:

$$
\begin{aligned}
& F\left(p_{1}\right)=\frac{d p_{1}}{d t}=p_{1}\left(E_{p_{1}}-\bar{E}_{p_{1}}\right)=p_{1}\left(1-p_{1}\right)\left(E_{p_{1}}-E_{1-p_{1}}\right)= \\
& p_{1}\left(1-p_{1}\right)\left[\begin{array}{l}
-p_{2} p_{3}\left(-F_{c}^{\alpha}+\lambda \delta \psi L_{l o}{ }^{\beta}-\lambda \delta L_{l o}{ }^{\beta}\right)+p_{2}\left(-F_{s}^{\alpha}-F_{c}^{\alpha}+\lambda \delta \psi L_{l o}{ }^{\beta}-\lambda \delta L_{l o}{ }^{\beta}\right) \\
+p_{3}\left(-F_{c}^{\alpha}+\lambda \delta \psi L_{l o}{ }^{\beta}-\lambda \delta L_{l o}{ }^{\beta}\right)+\left(C_{l r}-C_{s r}+F_{c}^{\alpha}+F_{s}^{\alpha}-\lambda \delta \psi L_{l o}{ }^{\beta}+\lambda \delta L_{l o}{ }^{\beta}+\lambda P_{g o}{ }^{\beta}\right)
\end{array}\right] .
\end{aligned}
$$

The influence of $p_{1}$ on the evolutionary stable equilibrium strategy of the project owner is calculated as:

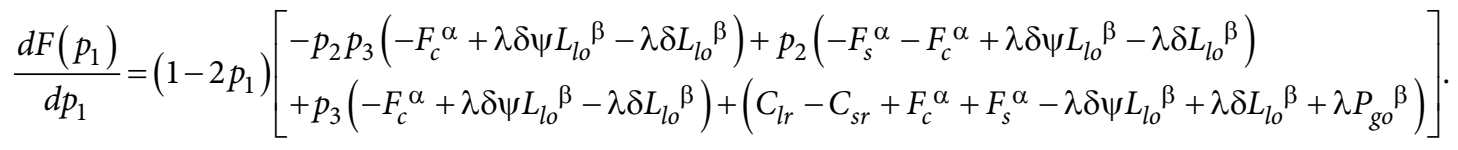

According to the stability theorem of dynamic replication differential equation (Taylor \& Jonker, 1978), only when $F\left(p_{1}\right)=d p_{1} / d t=0, d F\left(p_{1}\right) / d p_{1}<0$, the project owner's participation strategy reaches the evolution stability strategy. Solutions of $F\left(p_{1}\right)=0$ are $p_{1}=0, p_{1}=1$, and

$P_{2}^{*}=\frac{p_{3}\left(-F_{c}^{\alpha}+\lambda \delta \psi L_{l o}{ }^{\beta}-\lambda \delta L_{l o}{ }^{\beta}\right)+\left(C_{l r}-C_{s r}+F_{c}{ }^{\alpha}+F_{s}^{\alpha}-\lambda \delta \psi L_{l o}{ }^{\beta}+\lambda \delta L_{l o}{ }^{\beta}+\lambda P_{g o}{ }^{\beta}\right)}{p_{3}\left(-F_{c}^{\alpha}+\lambda \delta \psi L_{l o}{ }^{\beta}-\lambda \delta L_{l o} \beta\right)+\left(F_{s}^{\alpha}+F_{c}^{\alpha}-\lambda \delta \psi L_{l o}{ }^{\beta}+\lambda \delta L_{l o}{ }^{\beta}\right)}$. Accordingly, the replication dynamic phase diagram of the project owner is shown in Figure 2. Further detailed analysis is as follows.

When $p_{2}=P_{2}^{*}, F\left(p_{1}\right)=0$, which means any value of $p_{1}$ is in a stable state. The strategy of the project owner does not change based on time, as shown in Figure 2a. According to Eqns (20) and (21), when $p_{2}>P_{2}^{*}$, the $\left\{\begin{array}{l}d F\left(p_{1}\right) / d p_{1}<0, p_{1}=0 \\ d F\left(p_{1}\right) / d p_{1}>0, p_{1}=1\end{array}\right.$ can be obtained. Hence, $p_{1}=0$ is the equilibrium stable strategy, as shown in Figure $2 \mathrm{~b}$. The result indicates that the perceived value of the project owner to the input cost is greater than the returns obtained. The project owner shifts from limited rationality to risk appetite when faced with losses. Prefer to bear undue expenses and accident losses rather than to bear deterministic costs. That is, the project owner tends to choose the loose regulation strategy. The project owner is responsible for the overall planning and quality safety maintenance of MIPs, which is indispensable in supervision. The government can adopt severe penalties to increase the psychological perceived value of penalties to project owners to participate in the supervision of MIPs actively. When $p_{2}<P_{2}^{*}$, the $\left\{\begin{array}{l}d F\left(p_{1}\right) / d p_{1}<0, p_{1}=1 \\ d F\left(p_{1}\right) / d p_{1}>0, p_{1}=0\end{array}\right.$ can be obtained. Hence, $p_{1}=$ 1 is the equilibrium stable strategy, as shown in Figure 2c. The result indicates that the perceived benefits to the project owner of implementing a strict regulation strategy are greater than its regulation costs and penalties imposed by superior governments. If the project owner does not adopt a strict regulation strategy, it may bear undue expenses and accident losses. According to the prospect theory, it is known that the game players will turn to be risk-averse and unwilling to bear losses in the face of gains. Therefore, the project owner tends to choose the strict regulation strategy.

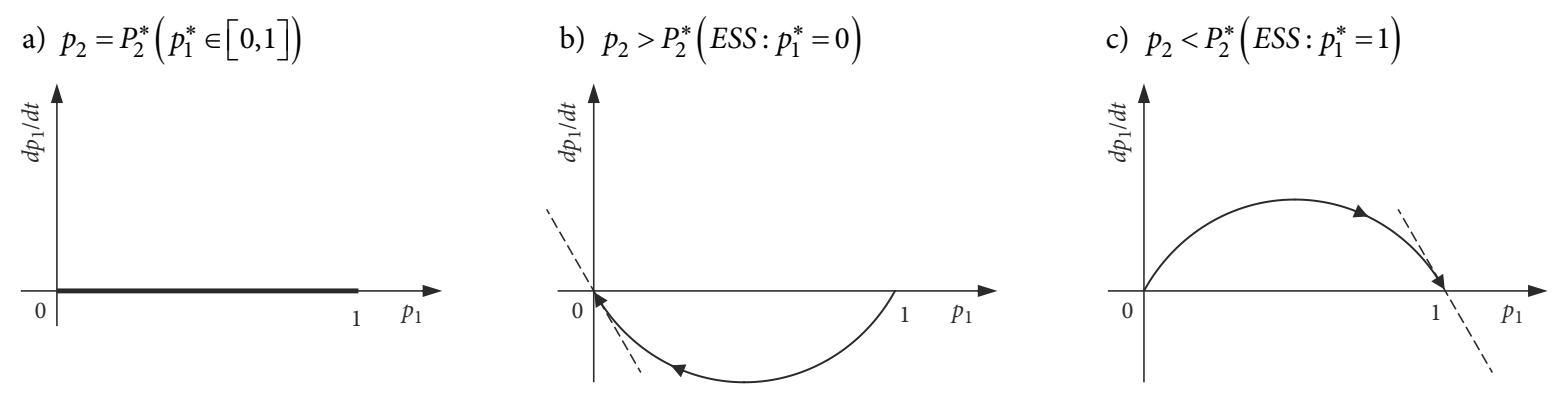

Figure 2. The replication dynamic phase diagram of the project owner

\subsubsection{The evolutionary stability strategies of supervision unit}

According to the prospect values obtained from the above analysis, the expected prospect value of the rejecting rentseeking and accepting rent-seeking strategies of supervision unit can be obtained as follows:

$$
\begin{aligned}
& E_{p_{2}}=-C_{r s}+M ; \\
& E_{1-p_{2}}=p_{1}\left(-\lambda F_{s}^{\beta}\right)+p_{3}\left(-B^{\alpha}\right)+\left(-C_{a s}+M+B^{\alpha}\right) .
\end{aligned}
$$


According to Eqns (22)-(23), the dynamic replication equation $F\left(p_{2}\right)$ of the supervision unit can be obtained as follows:

$$
F\left(p_{2}\right)=\frac{d p_{2}}{d t}=p_{2}\left(E_{p_{2}}-\bar{E}_{p_{2}}\right)=p_{2}\left(1-p_{2}\right)\left(E_{p_{2}}-E_{1-p_{2}}\right)=p_{2}\left(1-p_{2}\right)\left[p_{1}\left(\lambda F_{s}^{\beta}\right)+p_{3}\left(B^{\alpha}\right)+\left(C_{a s}-C_{r s}-B^{\alpha}\right)\right] .
$$

The influence of $p_{2}$ on the evolutionary stable equilibrium strategy of the supervision unit is calculated as:

$$
\frac{d F\left(p_{2}\right)}{d p_{2}}=\left(1-2 p_{2}\right)\left[p_{1}\left(\lambda F_{s}^{\beta}\right)+p_{3}\left(B^{\alpha}\right)+\left(C_{a s}-C_{r s}-B^{\alpha}\right)\right] .
$$

According to the stability theorem of dynamic replication differential equation, only when $F\left(p_{2}\right)=d p_{2} / d t=0$, $d F\left(p_{2}\right) / d p_{2}<0$, the supervision unit's participation strategy reaches the evolution stability strategy. Solutions of $F\left(p_{2}\right)=0$ are $p_{2}=0, p_{2}=1$, and $P_{3}^{*}=\frac{\left(C_{r s}-C_{a s}+B^{\alpha}\right)-p_{1}\left(\lambda F_{s}^{\beta}\right)}{B^{\alpha}}$. Accordingly, the replication dynamic phase diagram of the supervision unit is shown in Figure 3. Further detailed analysis is as follows.

When $p_{3}=P_{3}^{*}, F\left(p_{2}\right)=0$, which means any value of $p_{2}$ is in a stable state, that is, the strategy of the supervision unit does not change based on time, as shown in Figure 3a. According to Eqns (24) and (25), when $p_{3}>P_{3}^{*}$, the $\left\{\begin{array}{l}d F\left(p_{2}\right) / d p_{2}<0, p_{2}=1 \\ d F\left(p_{2}\right) / d p_{2}>0, p_{2}=0\end{array}\right.$ can be obtained. That is, $p_{2}=1$ is the equilibrium stable strategy, as shown in Figure $3 \mathrm{~b}$. The result shows that the punishment received by the supervision unit when choosing the rent-seeking behavior strategy is more than the extra income obtained under the strategy. If the supervision unit accepts rent-seeking behavior, it will be faced with deterministic loss. The supervision unit changes from limited rationality to risk preference. It tends to choose the decision to abide by the contract, that is, the strategy of rejecting rent-seeking behavior. When $p_{3}<P_{3}^{*}$, the $\left\{\begin{array}{l}d F\left(p_{2}\right) / d p_{2}<0, p_{2}=0 \\ d F\left(p_{2}\right) / d p_{2}>0, p_{2}=1\end{array}\right.$ can be obtained. Hence, $p_{2}=0$ is the equilibrium stable strategy, as shown in Figure $3 c$. The result shows that the punishment received by the supervision unit when choosing the rent-seeking behavior strategy is less than the extra income obtained under the strategy. As a result, the supervision unit often tends to the strategy of rentseeking behavior in order to seek personal benefits. The project owner should strengthen the supervision and increase the punishment to the supervision unit to prevent rent-seeking behavior.

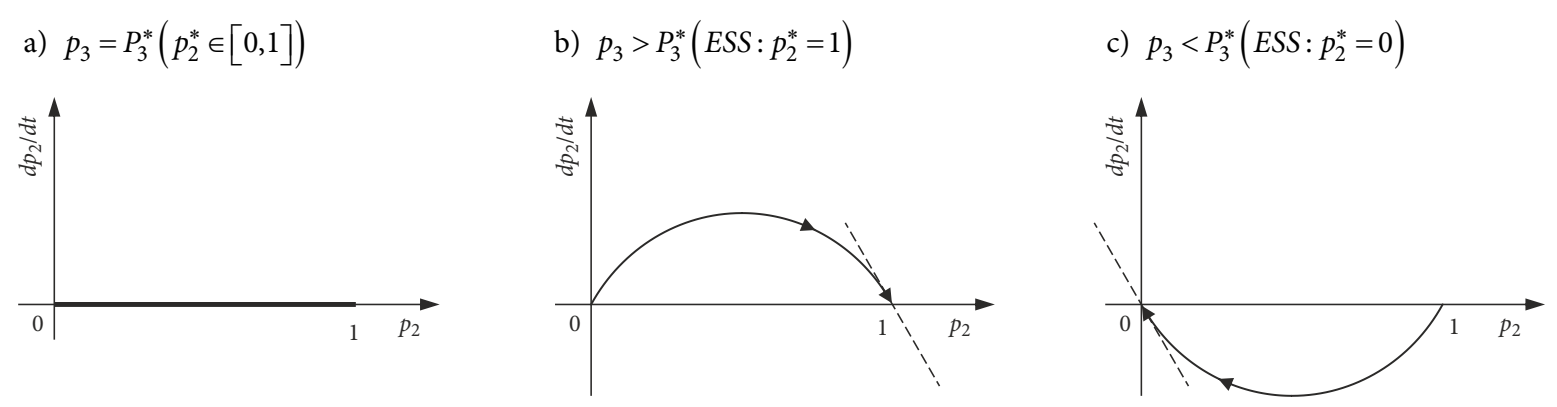

Figure 3. The replication dynamic phase diagram of the supervision unit

\subsubsection{The evolutionary stability strategies of project contractor}

According to the prospect values obtained from the above analysis, the expected prospect value of the strict regulation and loose regulation strategies of the project contractor can be obtained as follows:

$$
\begin{aligned}
& E_{p_{3}}=-C_{s c}+N \\
& E_{1-p_{3}}=p_{1} p_{2}\left(\lambda F_{c}^{\beta}+\lambda \delta \psi L_{l c}^{\beta}\right)+p_{1}\left(-\lambda F_{c}^{\beta}-\lambda \delta \psi L_{l c}^{\beta}\right)+p_{2}\left(-\lambda F_{c}^{\beta}-\lambda \delta \psi L_{l c}^{\beta}+\lambda B^{\beta}\right)+\left(-C_{n s}+N-\lambda B^{\beta}\right) .
\end{aligned}
$$

According to Eqns (26)-(27), the dynamic replication equation $F\left(p_{3}\right)$ of the project contractor can be obtained as follows:

$$
F\left(p_{3}\right)=\frac{d p_{3}}{d t}=p_{3}\left(E_{p_{3}}-\bar{E}_{p_{3}}\right)=p_{3}\left(1-p_{3}\right)\left(E_{p_{3}}-E_{1-p_{3}}\right)=p_{3}\left(1-p_{3}\right)\left[\begin{array}{c}
-p_{1} p_{2}\left(\lambda F_{c}^{\beta}+\lambda \delta \psi L_{l c}{ }^{\beta}\right)+p_{1}\left(\lambda F_{c}^{\beta}+\lambda \delta \psi L_{l c}{ }^{\beta}\right) \\
-p_{2}\left(-\lambda F_{c}^{\beta}-\lambda \delta \psi L_{l c}{ }^{\beta}+\lambda B^{\beta}\right)+\left(C_{n s}-C_{s c}+\lambda B^{\beta}\right)
\end{array}\right] .
$$


The influence of $p_{3}$ on the evolutionary stable equilibrium strategy of the project contractor is calculated as:

$$
\frac{d F\left(p_{3}\right)}{d p_{3}}=\left(1-2 p_{3}\right)\left[\begin{array}{l}
-p_{1} p_{2}\left(\lambda F_{c}^{\beta}+\lambda \delta \psi L_{l c}{ }^{\beta}\right)+p_{1}\left(\lambda F_{c}^{\beta}+\lambda \delta \psi L_{l c}{ }^{\beta}\right) \\
-p_{2}\left(-\lambda F_{c}^{\beta}-\lambda \delta \psi L_{l c}{ }^{\beta}+\lambda B^{\beta}\right)+\left(C_{n s}-C_{s c}+\lambda B^{\beta}\right)
\end{array}\right]
$$

According to the stability theorem of dynamic replication differential equation, only when $F\left(p_{3}\right)=d p_{3} / d t=0$, $d F\left(p_{3}\right) / d p_{3}<0$, the project contractor's participation strategy reaches the evolution stability strategy. Solution of $F\left(p_{3}\right)=0$ are $p_{3}=0, p_{3}=1$, and $p_{1}=\frac{p_{2}\left(-\lambda F_{c}^{\beta}-\lambda \delta \psi L_{l c}{ }^{\beta}+\lambda B^{\beta}\right)-\left(C_{n s}-C_{s c}+\lambda B^{\beta}\right)}{\left(1-p_{2}\right)\left(\lambda F_{c}^{\beta}+\lambda \delta \psi L_{l c}{ }^{\beta}\right)}=P_{1}^{*}$ can be obtained. Accordingly, the replication dynamic phase diagram of the project contractor is shown in Figure 4. Further detailed analysis is as follows.

When $p_{1}=P_{1}^{*}, F\left(p_{3}\right)=0$, which means any value of $p_{3}$ is in a stable state, that is, the strategy of the project contractor does not change based on time, as shown in Figure 4a. According to Eqns (28) and (29), when $p_{1}>P_{1}^{*}$, the $\left\{\begin{array}{l}d F\left(p_{3}\right) / d p_{3}<0, p_{3}=1 \\ d F\left(p_{3}\right) / d p_{3}>0, p_{3}=0\end{array}\right.$ can be obtained. That is, $p_{3}=1$ is the equilibrium stable strategy, as shown in Figure $4 \mathrm{~b}$. The result indicates that the sum of the punishment and accident loss of the project contractor in carrying out the nonnormative construction is more than the extra profit obtained under the strategy. The project contractor is transformed from limited rationality to risk preference in the face of losses. That is, the project contractor tends to choose the normative construction strategy. When $p_{1}<P_{1}^{*}$, the $\left\{\begin{array}{l}d F\left(p_{3}\right) / d p_{3}<0, p_{3}=0 \\ d F\left(p_{3}\right) / d p_{3}>0, p_{3}=1\end{array}\right.$ can be obtained. Hence, $p_{3}=0$ is the equilibrium stable strategy, as shown in Figure 4c. The result indicates that the sum of the punishment, accidental loss, and rent of the contractor in carrying out the non-normative construction is less than the extra profit obtained under the strategy. The project contractor tends to choose the non-normative construction strategy to reduce the expenditure and obtain excess profit.

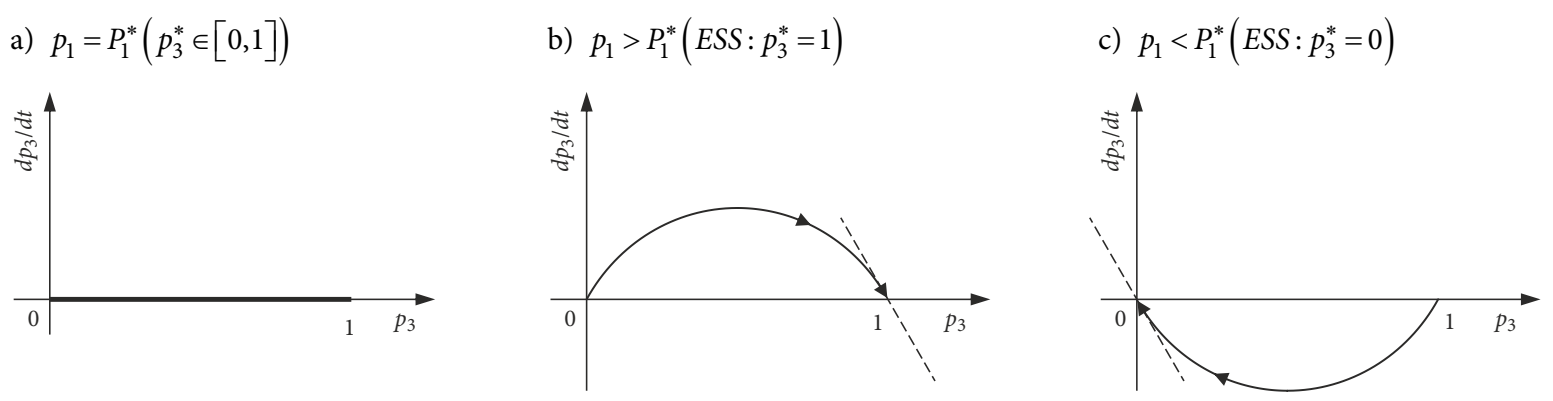

Figure 4. The replication dynamic phase diagram of the project contractor

\subsection{The mixed stability strategy of the game players}

It is worth noting that the equilibrium point is not all evolutionary stable strategy, since evolutionary stable strategy must also possess the ability to resist the error or deviation caused by bounded rationality, i.e., the ability to recover to a stable point after disturbance. As such, in order to explore the tripartite evolutionary stable strategy, the partial asymptotic stability method can be used for the Jacobian matrix to ascertain whether equilibrium point of the evolutionary system is stable (Friedman, 1998). According to the replication dynamic Eqns (20), (24), and (28), the Jacobian matrix $J_{F}\left(p_{1}, p_{2}, p_{3}\right)$ of the game system can be obtained follows:

$$
\begin{aligned}
& J_{F}\left(p_{1}, p_{2}, p_{3}\right)=\left[\begin{array}{lll}
\partial F\left(p_{1}\right) / \partial p_{1} & \partial F\left(p_{1}\right) / \partial p_{2} & \partial F\left(p_{1}\right) / \partial p_{3} \\
\partial F\left(p_{2}\right) / \partial p_{1} & \partial F\left(p_{2}\right) / \partial p_{2} & \partial F\left(p_{2}\right) / \partial p_{3} \\
\partial F\left(p_{3}\right) / \partial p_{1} & \partial F\left(p_{3}\right) / \partial p_{2} & \partial F\left(p_{3}\right) / \partial p_{3}
\end{array}\right]=
\end{aligned}
$$

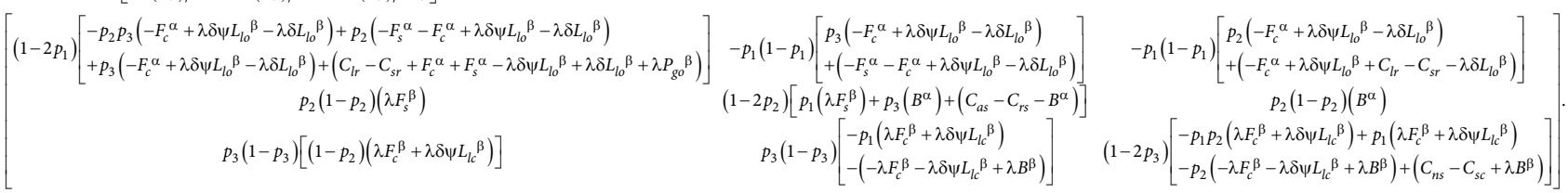

To further test the uniqueness of evolutionary stable equilibrium, this paper also carries out the Jacobian test. Firstly, set the dynamic replication equations $F\left(p_{1}, p_{2}, p_{3}\right)=0$. Then twelve partial equilibrium points of evolutionary game system can be obtained, namely, $E_{1}=(0,0,0), E_{2}=(0,0,1), E_{3}=(0,1,0), E_{4}=(0,1,1), E_{5}=(1,0,0)$, 
$E_{6}=(1,0,1), \quad E_{7}=(1,1,0), \quad E_{8}=(1,1,1), \quad E_{9}=\left(1, p_{2}=\frac{C_{n s}-C_{s c}+\lambda B^{\beta}+\lambda F_{c}^{\beta}+\lambda \delta \psi L_{l c}{ }^{\beta}}{\lambda B^{\beta}}, \frac{C_{r s}-C_{a s}-\lambda F_{s}^{\beta}+B^{\alpha}}{B^{\alpha}}\right)$, $E_{10}=\left(\frac{C_{s c}-C_{n s}-\lambda B^{\beta}}{\lambda F_{c}^{\beta}+\lambda \delta \psi L_{l c}{ }^{\beta}}, 0, \frac{C_{l r}-C_{s r}+F_{c}^{\alpha}+F_{s}^{\alpha}+\lambda \delta L_{l o}{ }^{\beta}-\lambda \delta \psi L_{l o}{ }^{\beta}+\lambda P_{g o}{ }^{\beta}}{F_{c}^{\alpha}+\lambda \delta L_{l o}{ }^{\beta}-\lambda \delta \psi L_{l o}{ }^{\beta}}\right), E_{11}=\left(\frac{C_{r s}-C_{a s}}{\lambda F_{s}^{\beta}}, \frac{F_{s}^{\alpha}+C_{l r}-C_{s r}}{F_{s}^{\alpha}}, 1\right)$, and $E_{12}=\left(\frac{B^{\alpha}-C_{a s}+C_{r s}}{\lambda F_{s}^{\beta}}, \frac{C_{l r}-C_{s r}+F_{c}^{\alpha}+F_{s}^{\alpha}-\lambda \delta \psi L_{l o}{ }^{\beta}+\lambda \delta L_{l o}{ }^{\beta}+\lambda P_{g o}{ }^{\beta}}{F_{s}{ }^{\alpha}+F_{c}^{\alpha}-\lambda \delta \psi L_{l o}{ }^{\beta}+\lambda \delta L_{l o}{ }^{\beta}}, 0\right)$. According to the ten partial equilibrium points, it can be seen that partial equilibrium points $E_{1} \sim E_{12}$ meets the conditions $0 \leq p_{1} \leq 1,0 \leq p_{2} \leq 1,0 \leq p_{3} \leq 1$ and constitutes the boundary of the evolutionary game, and partial equilibrium point $E_{9}-E_{12}$ exists in this region. For example, the Jacobian matrix of the game system at $E_{9}$ is as follows:

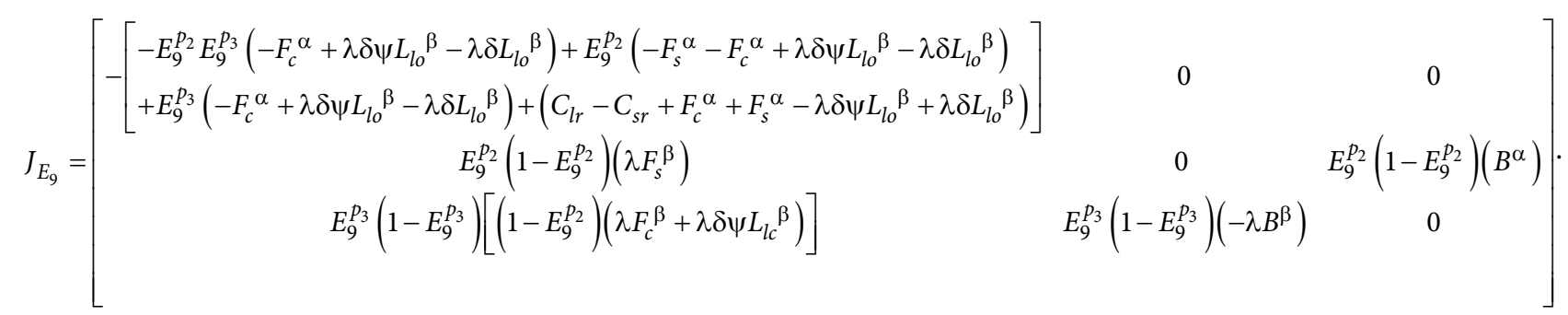

The eigenvalues of Jacobian matrix $J_{E 9}$ is zero, so $E_{9}$ are not asymptotic stable points of the system. Similarly, it can be concluded that there is no asymptotic stability point of the system at $E_{10}-E_{12}$. Therefore, this paper only discusses the stability of the other eight equilibrium points. MIPs are invested mainly by the government and involve the economic and social interests of the country and the public. Suppose the project owner is negative in supervision. In that case, the superior government will punish it severely, so that the additional income gained by the project owner in negative supervision is less than the penalty loss suffered, i.e., $C_{s r}-C_{l r}<\lambda P_{g o}{ }^{\beta}$. According to the Lyapunov indirect method, when all eigenvalues of the Jacobian matrix are less than 0 , the equilibrium point is the evolutionary stable strategy (Deptula et al., 2018; Licitra et al., 2019). According to the Jacobian matrix, the eigenvalues of eight partial equilibrium points can be solved and the attributes are judged accordingly. The eigenvalues and attributes of each equilibrium point are shown in Table 3.

Table 3. Stability analysis of equilibrium point of game system

\begin{tabular}{|c|c|c|c|c|}
\hline Equilibrium point & Eigenvalues & Conditions & Symbol & Attributes \\
\hline \multirow{3}{*}{$E_{1}=(0,0,0)$} & $C_{l r}-C_{s r}+F_{c}^{\alpha}+F_{s}^{\alpha}-\lambda \delta \psi L_{l o}{ }^{\beta}+\lambda \delta L_{l o}^{\beta}+\lambda P_{g o}^{\beta}$ & \multirow{3}{*}{1} & + & \multirow{3}{*}{ Saddle Point } \\
\hline & $C_{a s}-C_{r s}-B^{\alpha}$ & & - & \\
\hline & $C_{n s}-C_{s c}+\lambda B^{\beta}$ & & \pm & \\
\hline \multirow{3}{*}{$E_{2}=(0,0,1)$} & $C_{l r}-C_{s r}+F_{s}^{\alpha}+\lambda P_{g o}^{\beta}$ & \multirow{3}{*}{1} & + & \multirow{3}{*}{ Saddle Point } \\
\hline & $C_{a s}-C_{r s}$ & & - & \\
\hline & $-\left(C_{n s}-C_{s c}+\lambda B^{\beta}\right)$ & & \pm & \\
\hline \multirow{3}{*}{$E_{3}=(0,1,0)$} & $C_{l r}-C_{s r}+\lambda P_{g o} \beta$ & \multirow{3}{*}{1} & + & \multirow{3}{*}{ Saddle Point } \\
\hline & $-\left(C_{a s}-C_{r s}-B^{\alpha}\right)$ & & + & \\
\hline & $-\left(\lambda F_{c}^{\beta}+\lambda \delta \psi L_{l c}{ }^{\beta}+C_{n s}-C_{s c}\right)$ & & \pm & \\
\hline \multirow{3}{*}{$E_{4}=(0,1,1)$} & $C_{l r}-C_{s r}+\lambda P_{g o}{ }^{\beta}$ & \multirow{3}{*}{ l } & + & \multirow{3}{*}{ Saddle Point } \\
\hline & $-\left(C_{a s}-C_{r s}\right)$ & & + & \\
\hline & $-\left(\lambda F_{c}^{\beta}+\lambda \delta \psi L_{l c}{ }^{\beta}+C_{n s}-C_{s c}\right)$ & & \pm & \\
\hline
\end{tabular}


End of Table 3

\begin{tabular}{|c|c|c|c|c|}
\hline Equilibrium point & Eigenvalues & Conditions & Symbol & Attributes \\
\hline \multirow{3}{*}{$E_{5}=(1,0,0)$} & $-\left(C_{l r}-C_{s r}+F_{c}^{\alpha}+F_{s}^{\alpha}-\lambda \delta \psi L_{l o}^{\beta}+\lambda \delta L_{l o}^{\beta}+\lambda P_{g o}^{\beta}\right)$ & \multirow{3}{*}{$\begin{array}{l}C_{r s}-C_{a s}>\lambda F_{s}^{\beta}-B^{\alpha} \\
C_{s c}-C_{n s}>\lambda B^{\beta}+\lambda F_{c}^{\beta}+\lambda \delta \psi L_{l c}^{\beta}\end{array}$} & - & \multirow{3}{*}{ ESS } \\
\hline & $C_{a s}-C_{r s}-B^{\alpha}+\lambda F_{s}^{\beta}$ & & - & \\
\hline & $C_{n s}-C_{s c}+\lambda B^{\beta}+\lambda F_{c}^{\beta}+\lambda \delta \psi L_{l c}^{\beta}$ & & - & \\
\hline \multirow{3}{*}{$E_{6}=(1,0,1)$} & $-\left(C_{l r}-C_{s r}+F_{s}^{\alpha}+\lambda P_{g o}^{\beta}\right)$ & \multirow[t]{3}{*}{$\begin{array}{l}C_{r s}-C_{a s}>\lambda F_{s}^{\beta} \\
C_{s c}-C_{n s}<\lambda B^{\beta}+\lambda F_{c}^{\beta}+\lambda \delta \psi L_{l c}^{\beta}\end{array}$} & - & \multirow{3}{*}{ ESS } \\
\hline & $C_{a s}-C_{r s}+\lambda F_{s}^{\beta}$ & & - & \\
\hline & $-\left(C_{n s}-C_{s c}+\lambda B^{\beta}+\lambda F_{c}^{\beta}+\lambda \delta \psi L_{l c}^{\beta}\right)$ & & - & \\
\hline \multirow{3}{*}{$E_{7}=(1,1,0)$} & $-\left(C_{l r}-C_{s r}+\lambda P_{g o}^{\beta}\right)$ & \multirow{3}{*}{$\begin{array}{l}C_{r s}-C_{a s}<\lambda F_{s}^{\beta}-B^{\alpha} \\
C_{s c}-C_{n s}>\lambda F_{c}^{\beta}+\lambda \delta \psi L_{l c}^{\beta}\end{array}$} & - & \multirow{3}{*}{ ESS } \\
\hline & $-\left(C_{a s}-C_{r s}-B^{\alpha}+\lambda F_{s}^{\beta}\right)$ & & - & \\
\hline & $C_{n s}-C_{s c}+\lambda F_{c}^{\beta}+\lambda \delta \psi L_{l c}^{\beta}$ & & - & \\
\hline$E_{8}=(1,1,1)$ & $-\left(C_{l r}-C_{s r}+\lambda P_{g o}^{\beta}\right)$ & $\begin{array}{l}C_{r s}-C_{a s}<\lambda F_{s}^{\beta} \\
C_{s c}-C_{n s}<\lambda F_{c}^{\beta}+\lambda \delta \psi L_{l c}^{\beta}\end{array}$ & - & ESS \\
\hline
\end{tabular}

\section{System dynamics simulation analysis}

\subsection{System dynamics evolutionary game model}

The simulation model does not lie in how real it is, but in its usefulness and the extent to which it reveals the regularity of changes in things (Si \& Zhu, 2008). The system dynamics model is concerned with the behavior trend of the whole system and the influence of policy changes, and it does not require very accurate results (Hu \& Shen, 2001). The correctness of the structure of the system dynamics model is more important than the choice of parameter values (Wu et al., 2010). Therefore, the selection of all simulation values in this paper mainly considers the sensitivity analysis for the change of various relevant variables to the strategy selection of the project owner, the supervision unit, and the project contractor. Each simulation value does not represent the payment or profit value of all parties in reality. In order to analyse the strategic interaction between project owner supervision unit and project contractor in a more systematic and in-depth way, this study used VENSIM @PLE7.3.5 to construct the system dynamic model for rent-seeking behavior supervision of MIPs according to Eqns (18), (19), (22), (23), (26), and (27), as shown in Figure 5. Then, this system dynamic model is employed to analyse the evolution of the strategic interaction and the influence of exogenous variables and parameters about prospect theory on the MIPs supervision system. The system dynamics simulation environment is set as follows: INITIAL TIME $=0$, FINAL TIME $=10$, TIME STEP $=0.0078125$, units for time take a year. The model variables and parameters are set as follows: $C_{s r}=2.50, C_{l r}=2.00, P_{g o}=1.00, R_{l p}=1.00, L_{l o}=0.20, L_{l c}=0.20, C_{r s}=3.00, C_{a s}=2.50, M=$ $4.00, B=1.00, F_{s}=1.00, C_{s c}=2.00, C_{n s}=1.00, N=4.00, F_{c}=1.00, \psi=0.5, \delta=0.5$.

\subsection{The analysis of the evolutionary process}

According to the experiment of Kahneman and Tversky (1979), the benefit risk attitude coefficient $(\alpha=0.52)$, the loss risk attitude coefficient $(\beta=0.88)$, and the loss avoidance coefficient $(\lambda=2.25)$ are determined for system dynamics simulation analysis. It is assumed that the project owner, the supervision unit, and the project contractor choose strict regulation strategy, rejecting rent-seeking strategy and conducting normative construction strategy, respectively, and their initial probability is 0.5 . When the initial evolution state is $(0.5,0.5,0.5)$, the evolution of the tripartite strategy is shown in Figure 6. $E_{8}=(1,1,1)$ is the evolutionary stable strategy. As can be seen from Figure 6, in the initial stage, the project owner carried out strict supervision strategy to encourage project contractors to conduct normative construction and guide supervision units to refuse rent-seeking. Finally, the rent-seeking behavior supervision system of MIPs achieves an evolutionary stable equilibrium $(1,1,1)$.

In addition, different initial probabilities have other effects on the evolution of the system, and the influence is shown in Figure 7. When the initial possibility is less than 0.5 , the speed of three parties in the game to choose strategies slows down. Conversely, when the initial probability is more than 0.5 , the speed of the three parties in the game to choose strategies is accelerated, indicating that the initial probability of three-party strategy in the game has a positive effect on the system evolution. 


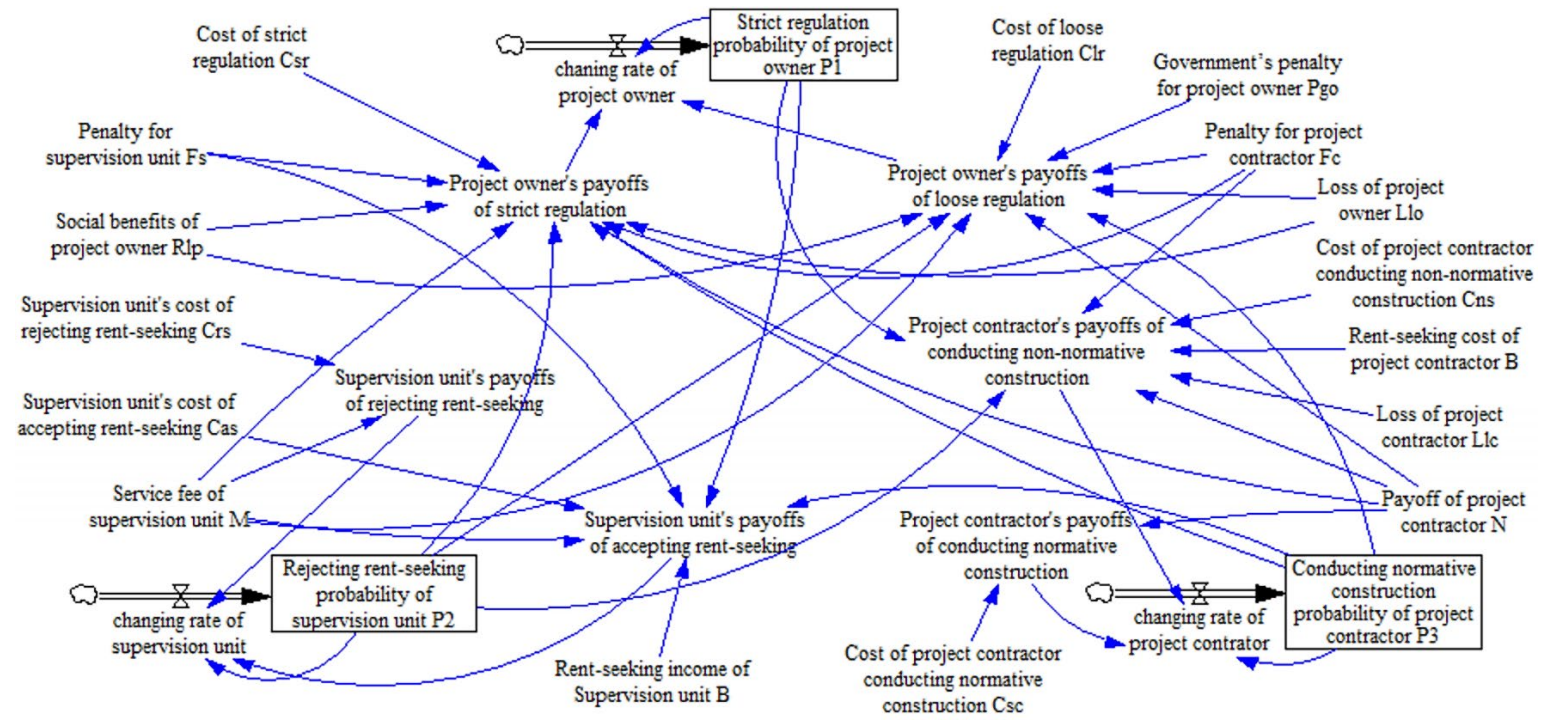

Figure 5. The system dynamic model for rent-seeking behavior supervision of MIPs

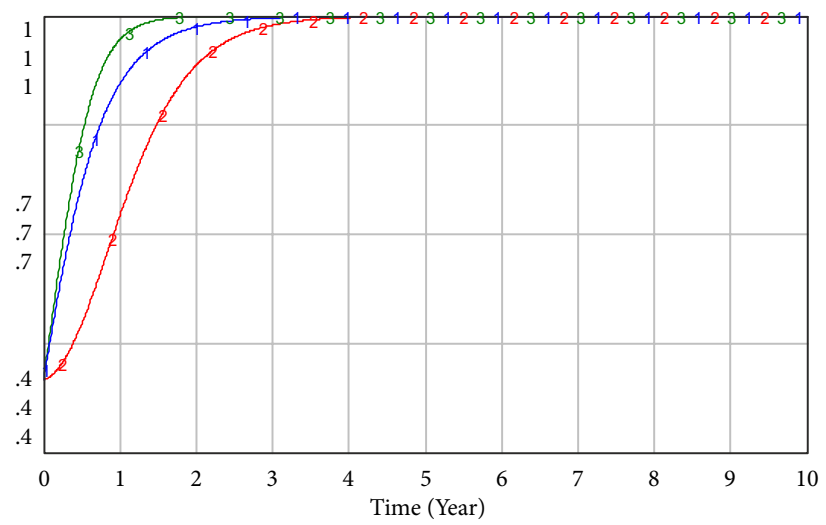

Strict regulation probability of project owner 4 1 $1,1,1,1,1,1,1$ P1: Current 1

Rejecting rent-seeking probability of supervision unit P2: Current 1

Conducting normative construction probability of project \begin{tabular}{lllllll}
\hline & 3 & 3 & 3 & 3
\end{tabular} contractor P3: Current 1

Figure 6. Evolutionary processes of rent-seeking behavior supervision

a) $p_{1}=p_{2}=p_{3}=0.1$

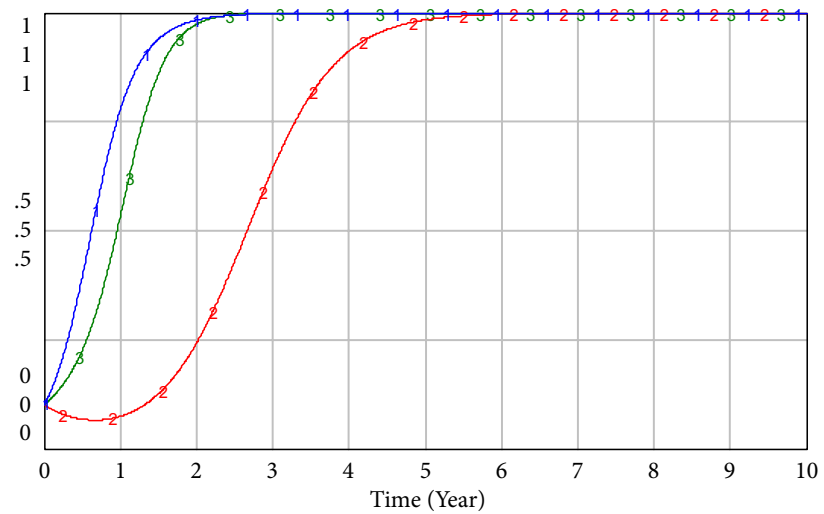

Strict regulation probability of project owner P1: Current 2

Rejecting rent-seeking probability of supervision $\begin{array}{lllllllllll}2 & 2 & 2 & 2 & 2 & 2 & 2 & 2\end{array}$ unit P2: Current 2

Conducting normative construction probability of project contractor P3: Current 2
b) $p_{1}=p_{2}=p_{3}=0.9$

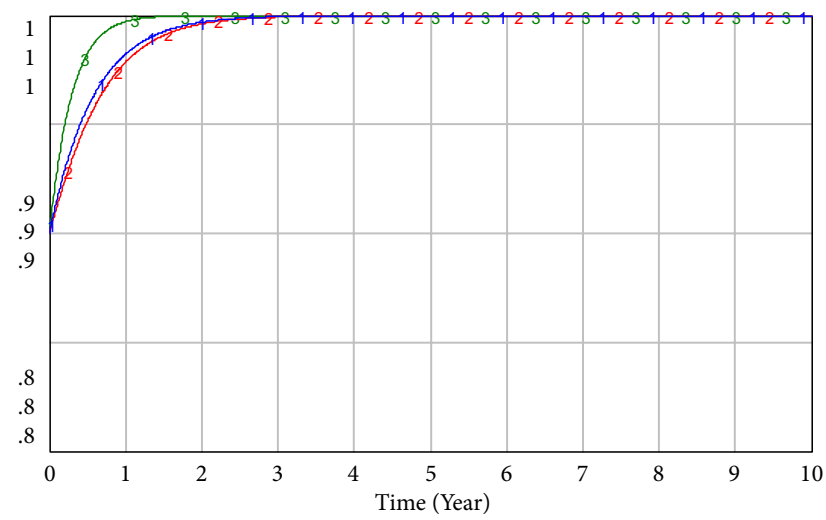

Strict regulation probability of project owner P1: Current 3

Rejecting rent-seeking probability of supervision $\begin{array}{llllllllll}2 & 2 & 2 & 2 & 2 & 2 & 2 & 2\end{array}$ unit P2: Current 3

Conducting normative construction probability of project contractor P3: Current 3

Figure 7. Influence of different initial probabilities on the evolution of the system 


\subsection{Analysis of the influence of exogenous variables}

In the supervision mechanism of MIPs, the project owner mainly restricts the supervision unit and the project contractor through the punishment mechanism. Therefore, this paper adopts the system dynamics simulation, and firstly analyses the influence of different punishment intensities on the strategy choice of the supervision unit and the project contractor. The evolution paths of the strategy choice are shown in Figures 8a and 8b, respectively. The Figure 8a: Current 1: $F_{s}=0$, Current 2: $F_{s}=0.1$, Current 3: $F_{s}=0.2$, Current 4: $F_{s}=0.5$, Current 5: $F_{s}=1.0$. The Figure 8b: Current 1: $F_{c}=0$, Current 2: $F_{c}=0.3$, Current 3: $F_{c}=0.5$, Current 4: $F_{c}=0.7$, Current 5: $F_{c}=1.0$. It is not difficult to see that with the increase of $F_{s}$ and $F_{c}$, the speed of the project contractor and the supervision unit approaching evolutionary stable strategy has accelerated. With the increase of $F_{c}$, the speed of the project contractor approaching evolutionary stable strategy is accelerated a bit little, but the change is not obvious. It indicates that the project contractor's strategy choice is not sensitive to the change of penalty intensity. However, different $F_{s}$ can change the strategy choice of the supervision unit. Under the circumstance that the punishment is too light, such as $F_{s}=0$ and $F_{s}=0.1$, the supervision unit will conduct rentseeking activities driven by interests, which is not conducive to the safe construction of MIPs. However, when $F_{s}>0.2$, the strategy of the supervision unit is gradually changing. It can be seen that in the rent-seeking supervision system of MIPs, it is more effective to increase the punishment of the supervision unit than the punishment of the project contractor. Therefore, the project owner should increase penalties to urge the project contractor to strictly perform the contract terms and specifications and prevent the supervision unit from seeking rent.

As can be seen from Table 3, the main exogenous variables affecting the evolution results of the rent-seeking behavior supervision system of MIPs are also $C_{r s}, C_{a s}, C_{s c}, C_{n s}, B$, and $L_{l c}$. Based on the above model, the influence of different input costs on the strategy choice of the supervision unit and project contractor is discussed. The evolution paths of the strategy choice are shown in Figures 9a and 9b, respectively. The Figure 9a: Current 1: $C_{r s}=3.0, C_{a s}=2.5$, Current 2: $C_{r s}=3.0, C_{a s}=2.0$, Current 3: $C_{r s}=4.0, C_{a s}=1.0$. The Figure 9b: Current 1: $C_{s c}=2.0, C_{n s}=1.0$, Current 2: $C_{s c}=5.0$, $C_{n s}=0.5$, Current 3: $C_{s c}=6.0, C_{n s}=0.5$. It is easy to see from the Figure 9 that when the cost difference between the two strategies reaches a certain level, the supervision unit and project contractor will choose to accept the rent-seeking strategy and the non-normative construction strategy, respectively. That is, the supervision unit and project contractor will engage in collusive activities when the additional benefits they gain from choosing these strategies are greater than the penalties and losses. And it can be seen that the larger the cost difference, less iterations are needed to reach the evolutionary stable equilibrium.

The influence of the rent-seeking payoff/cost $B$ and loss of project contractor $L_{l c}$ on the strategy selection of the project owner, the supervision unit and the project contractor are shown in Figures 10a, 10b and 10c, respectively. The Figures 10a and 10b: Current 1: $B=1.0$, Current 2: $B=2.0$, Current 3: $B=3.0$. The Figure 10c: Current 1: $L_{l c}=0$, Current 2: $L_{l c}=$ 0.2, Current 3: $L_{l c}=0.4$. Different rent-seeking payoff/cost $B$ and loss of project contractor $L_{l c}$ do not affect the final evolutionary results of the rent-seeking supervision system of MIPs. As $B$ and $L_{l c}$ increases, the speed of the supervision unit and the project contractor approaching evolutionary stable strategy is accelerated a bit little, but none of these changes are significant. Therefore, the project owner can make use of the social supervision function of the media to increase the rent-seeking cost of the project contractor and reduce the rent-seeking income of the supervision unit, thus effectively promoting the normative construction of MIPs.

a) Influence of $F_{s}$ on the supervision unit

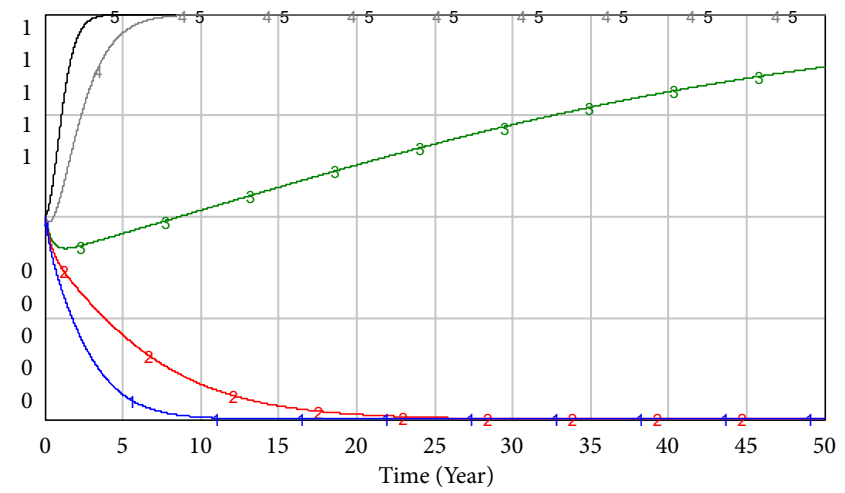

Rejecting rent-seeking probability of supervision unit P2: Current 1

Rejecting rent-seeking probability of supervision unit P2: Current 2

Rejecting rent-seeking probability of supervision unit P2: Current 3

Rejecting rent-seeking probability of supervision unit P2: Current 4

Rejecting rent-seeking probability of supervision unit P2: Current 5 b) Influence of $F_{c}$ on the supervision unit

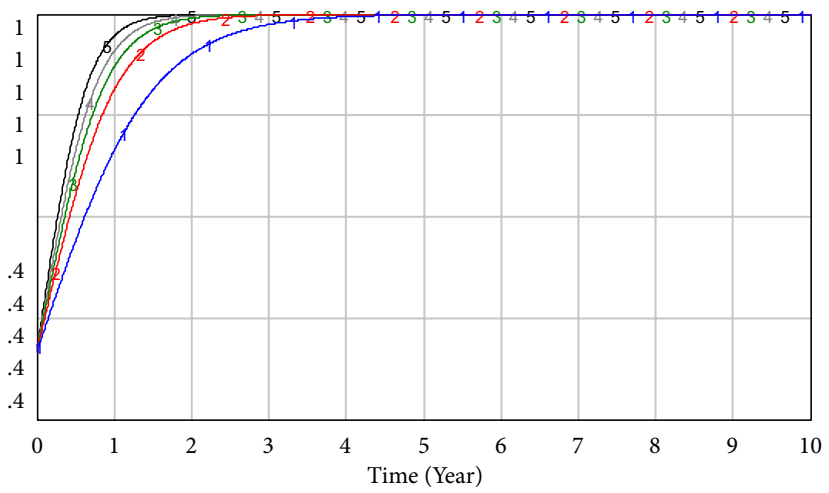

Conducting normative construction probability of project contractor P3: Current 1

Conducting normative construction probability

of project contractor P3: Current 2

Conducting normative construction probability

of project contractor P3: Current 3

Conducting normative construction probability

of project contractor P3: Current 4

Conducting normative construction probability

of project contractor P3: Current 5

Figure 8. Influence of different punishment intensity on the strategy selection of the supervision unit and project contractor 
a) Influence of $C_{r s}$ and $C_{a s}$ on the supervision unit

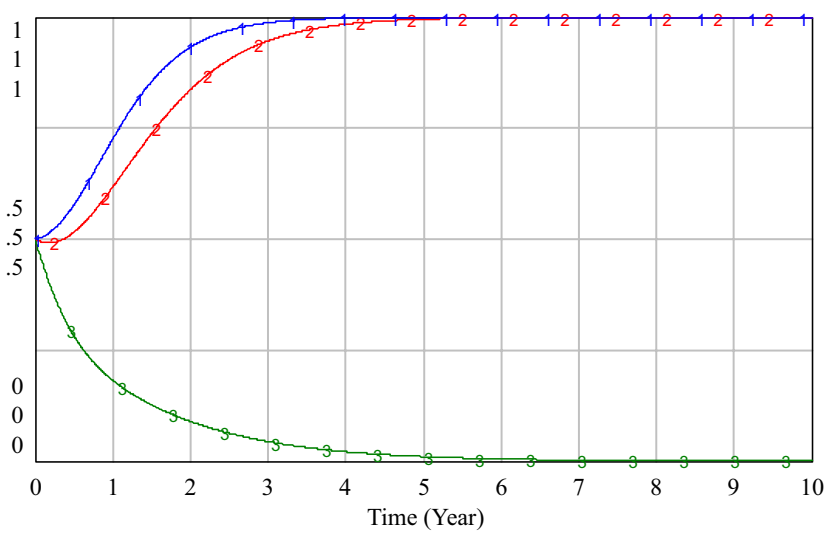

Rejecting rent-seeking probability of supervision unit P2: Current 1

Rejecting rent-seeking probability of supervision unit P2: Current 2

Rejecting rent-seeking probability of supervision unit P2: Current 3 b) Influence of $C_{s c}$ and $C_{n s}$ on the project contractor

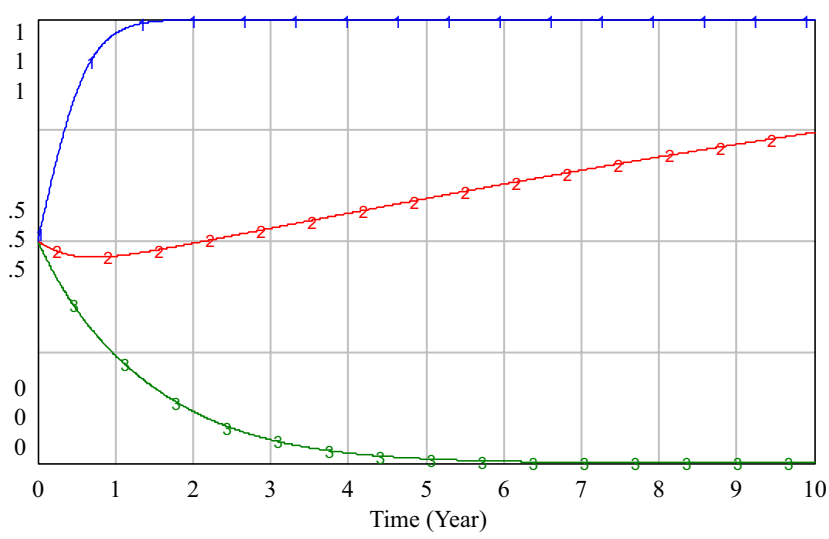

Conducting normative construction probability
of project contractor P3: Current 1
$\begin{aligned} & \text { Conducting normative construction probability } \\ & \text { of project contractor P3: Current 2 }\end{aligned}$
$\begin{aligned} & \text { Conducting normative construction probability } \\ & \text { of project contractor P3: Current 3 }\end{aligned}$

Figure 9. Influence of different cost on the strategy selection of the supervision unit and project contractor

a) Influence of $B$ on the supervision unit

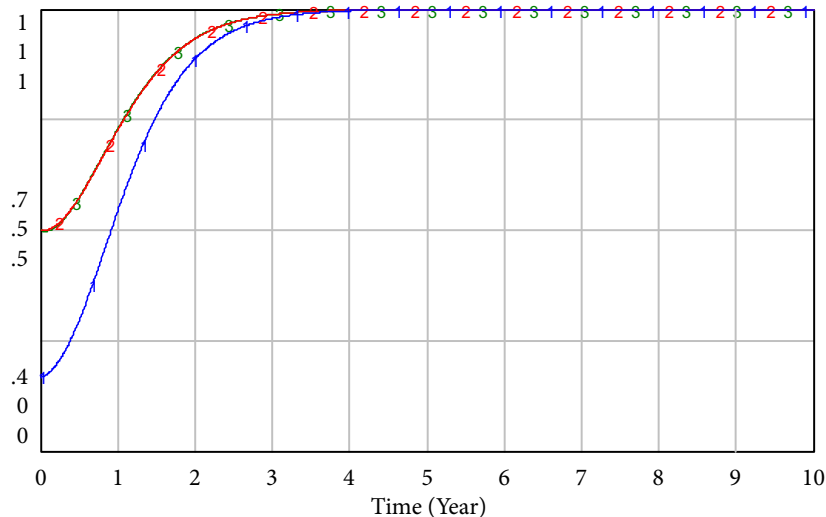

Rejecting rent-seeking probability of supervision unit P2: Current 1

Rejecting rent-seeking probability of supervision unit P2: Current 2

Rejecting rent-seeking probability of supervision unit P2: Current 3 b) Influence of $B$ on the project contractor

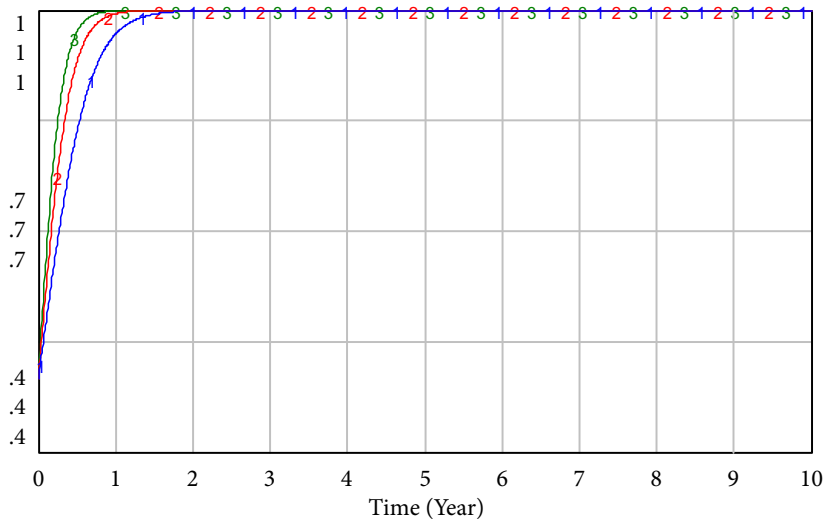

Conducting normative construction probability

of project contractor P3: Current 1

Conducting normative construction probability

of project contractor P3: Current 2

Conducting normative construction probability of project contractor P3: Current 3

c) Influence of $L_{l c}$ on the project contractor

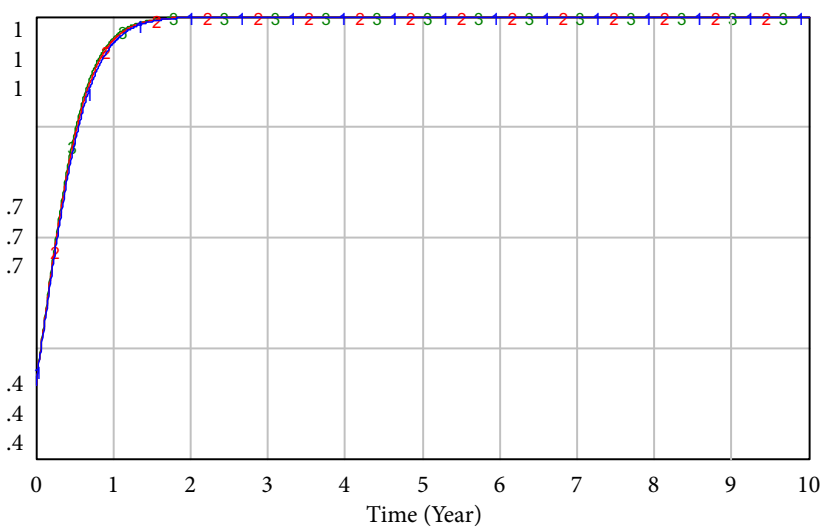

Conducting normative construction probability $\longrightarrow$

of project contractor P3: Current 1

Conducting normative construction probability 2 2 2

of project contractor P3: Current 2

Conducting normative construction probability

of project contractor P3: Current 3

Figure 10. Influence of different $B$ and $L_{l c}$ on the strategy selection of the supervision unit and the project contractor 


\subsection{Analysis of the influence of parameters related to prospect theory}

The influence of the change of loss avoidance coefficients $\lambda$ on the strategy choice of game players is shown in Figures $11 \mathrm{a}, 11 \mathrm{~b}$ and 11c. As shown in Figure 11: Current 1: $\lambda=1.0$, Current 2: $\lambda=2.0$, Current 3: $\lambda=2.25$. The change of loss avoidance coefficients $\lambda$ affects the strategy evolution speed of game players. With the increase of loss avoidance coefficients $\lambda$, the speed of $p_{1}, p_{2}, p_{3}$ approaching evolutionary stable strategy is accelerated. That is, the probability of the project owner, the supervision unit, and the project contractor choosing the evolutionary stability strategy is affected by the loss avoidance coefficients $\lambda$, and the influence on the supervision unit is more obvious. The higher the loss avoidance coefficients, the faster the evolution process of the game players choosing the stable strategy. It indicates that the larger the loss avoidance coefficients $\lambda$, the more sensitive the game players are to the loss. There is a certain deviation between the strategy evolution trend of the game players when $\lambda=1.0$ and the strategy evolution trend when $\lambda$ is larger. Therefore, the introduction of prospect theory to analyse the game process of the major infrastructure projects supervision system is more consistent with the actual situation. Similarly, different benefit risk attitude coefficients $\alpha$ and loss risk attitude coefficients $\beta$ do not affect the final evolutionary results of the regulatory system for major infrastructure projects, but affect the speed of strategic evolution. When the risk attitude coefficient $\alpha=\beta=1$, the game players is risk-neutral. There is a certain deviation between its strategy evolution trend and the strategy evolution trend with a smaller risk attitude coefficient. Therefore, the introduction of prospect theory to analyse the game process for supervision system of MIPs can better reflect the change of risk attitude of the game players.

a) The project owner

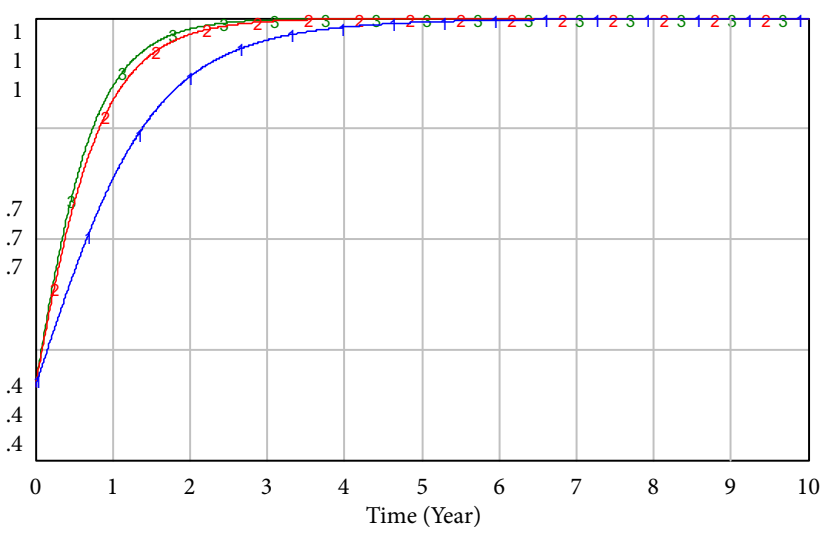

Strict regulation probability of project owner P1: Current 1

Strict regulation probability of project owne P1: Current 2

Strict regulation probability of project owner P1: Current 3 b) The supervision unit

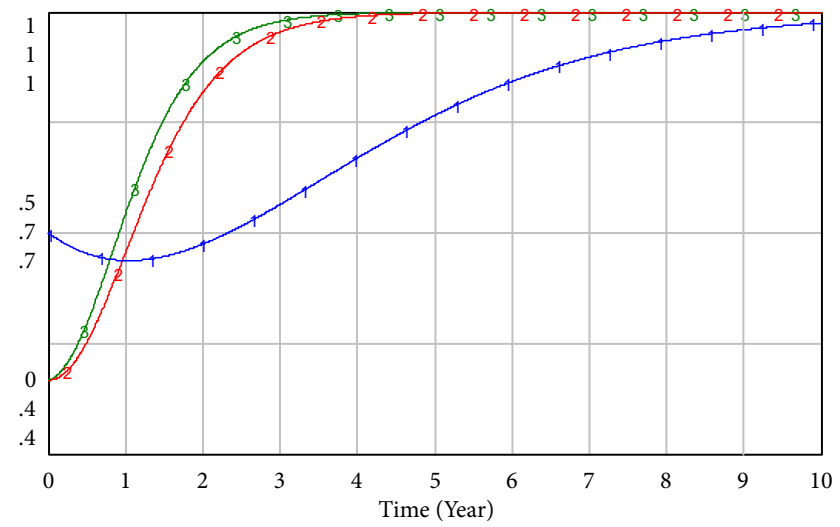

Rejecting rent-seeking probability of supervision unit P2: Current 1

Rejecting rent-seeking probability of supervision

unit P2: Current 2

Rejecting rent-seeking probability of supervision unit P2: Current 3

c) The project contractor

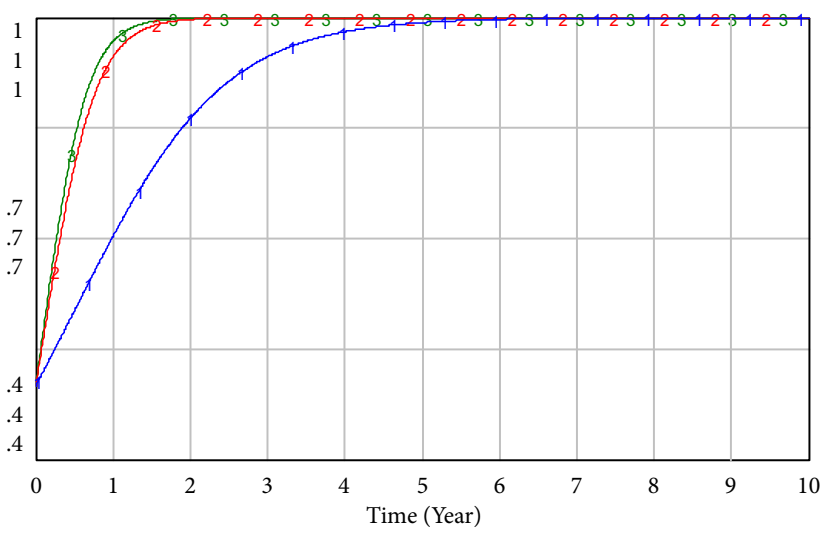

Conducting normative construction probability

of project contractor P3: Current 1

Conducting normative construction probability

of project contractor P3: Current 2

Conducting normative construction probability

of project contractor P3: Current 3

Figure 11. Influence of different loss avoidance coefficient on the strategy selection of game players 


\section{Discussion}

According to Table 3 and system dynamics simulation analysis, under the restrictions of some conditions, the tripartite evolutionary game system for the rent-seeking supervision system of major infrastructure projects reaches a stable state, that is, there are four evolutionary stable strategy (ESS).

When these parameters satisfy conditions $C_{r s}-C_{a s}>\lambda F_{s}^{\beta}-B^{\alpha}$ and $C_{s c}-C_{n s}>\lambda B^{\beta}+\lambda F_{c}^{\beta}+\lambda \delta \psi L_{l c}{ }^{\beta}$, the eigenvalues of $E_{5}=(1,0,0)$ are all negative value, so the ESS is \{strict regulation, accepting rent-seeking, non-normative construction\}. Similarly, when these parameters satisfy conditions $C_{r s}-C_{a s}<\lambda F_{s}^{\beta}-B^{\alpha}$ and $C_{s c}-C_{n s}>\lambda F_{c}^{\beta}+\lambda \delta \psi L_{l c}{ }^{\beta}$, the eigenvalues of $E_{7}=(1,1,0)$ are also all negative, so the ESS is \{strict regulation, rejecting rent-seeking, non-normative construction\}. In the above two cases, the strategy choice of the project contractor is non-normative construction. Therefore, it must be avoided that these parameters satisfy these conditions in the rent-seeking behavior supervision system of MIPs. When these parameters satisfy conditions $C_{r s}-C_{a s}>\lambda F_{s}^{\beta}$ and $C_{s c}-C_{n s}<\lambda B^{\beta}+\lambda F_{c}^{\beta}+\lambda \delta \psi L_{l c} \beta$, the eigenvalues of $E_{6}=(1,0,1)$ are all negative value, so the \{strict regulation, accepting rent-seeking, normative construction\} is the stable state of the system. This condition indicates that the perceived value of the supervision unit to punishment is less than the additional benefit obtained by adopting the rent-seeking strategy, and the perceived value of the project contractor to punishment, rent-seeking cost and accident loss is greater than the additional benefit obtained by adopting the non-normative construction strategy. In this case, the supervision unit plays a small role in the supervision, while the project owner bears a major supervisory responsibility. When the project owner conducts strict regulation and the project contractor selects normative construction, the quality and safety of the MIPs can be basically guaranteed. However, $E_{6}=(1,0,1)$ is not the optimal strategy in the rent-seeking behavior supervision system of MIPs. The project owner should increase the punishment of the supervision unit to make them actively supervise.

Similarly, when these parameters satisfy conditions $C_{r s}-C_{a s}<\lambda F_{s}^{\beta}$ and $C_{s c}-C_{n s}<\lambda F_{c}^{\beta}+\lambda \delta \psi L_{l c}{ }^{\beta}$, the eigenvalues of $E_{8}=(1,1,1)$ are all negative value, so the ESS is \{strict regulation, rejecting rent-seeking, normative construction\}. That is, When the perceived value of the supervision unit to punishment is greater than the difference between the cost of rejecting rent-seeking and accepting rent-seeking, and the perceived value of the project contractor to punishment and accident loss is greater than the additional benefit of conducting non-normative construction, the game system for rentseeking behavior supervision of MIPs reaches an ideal state. According to the prospect theory, the game players have the effect of loss avoidance. When the penalty and accident loss are much greater than the gain from the violation, the game players will actively engage in normative construction and management to avoid risks. Therefore, in order to establish an effective rent-seeking behavior supervision mechanism and achieve the goal of normative construction of MIPs, it is necessary to discuss the conditions that the optimal strategy satisfies. In the actual construction of MIPs, the game players of behavior have cognitive bias in the rent-seeking behavior supervision. The project contractor often believes that illegal construction will not cause major accidents and underestimate the probability and loss of accidents in MIPs. That is, $\pi(\delta)<\delta$ and $V\left(-L_{l c}\right)<L_{l c}$ hold, then $\pi(\delta) V\left(-L_{l c}\right)<\delta L_{l c}$, which indicates the perceived value of accident loss is less than the actual value. Due to the existence of speculative psychology, the project contractor believes that it is difficult for the project owner and supervision units to find non-normative construction behaviors due to inadequate supervision, and underestimates the probability and severity of punishment for violations. That is, $\pi(p)<p$ and $V\left(-F_{c}\right)<F_{c}$ hold, then $\pi(p) V\left(-F_{c}\right)<p F_{c}$, which indicates the perceived value of penalty loss is less than the actual value. More importantly, if the project owner and supervision unit underestimate the probability and loss of being punished by adopting loose regulation and rent-seeking $\left(\pi(p) V\left(-P_{g o}\right)<p P_{g o}, \pi(p) V\left(-F_{s}\right)<p F_{s}\right)$, the conditions for evolving into a stable strategy $E_{8}=(1,1,1)$ cannot be met simultaneously. In summary, due to the existence of cognitive bias, the tripartite game players will underestimate the probability of punishment for violations and accidents, and the perceived value of losses, thus making the system deviate from the ideal state. Therefore, in order to establish an effective rent-seeking behavior supervision mechanism, this paper proposed the following suggestions from the perspectives of the project owner, the supervision unit, and the project contractor.

First, for the project owner, from the perspective of ex-ante precautions, it is necessary to strengthen ex-ante precautions and improve the strict compliance awareness of the supervision unit and the project contractor (Gu et al., 2018). The project owner should increase the punishment to the supervision unit and the project contractor, increase their psychological perception value of punishment, and deeply realize that the rent-seeking behavior will suffer both economic and reputation loss $(\mathrm{Li}, 2017)$. From the perspective of the ex-post punishment mechanism. Economic, administrative and criminal punishments are used in a multi-pronged manner to increase the punishment for rent-seeking behavior (Xu \& Zhao, 2009; Wu \& Liu, 2013). The bribe-takers should be severely punished, while the bribe-givers can be treated with leniency in accordance with the law, so as to break the alliance between the two sides of the rent-seeking game. This situation increases the risk of bribe-takers and causes the alliance's failure, thus reducing rent-seeking behavior.

Second, for the supervision unit, the supervision unit's rent-seeking behavior may lead to accidents. In order to increase the effectiveness of project quality control, more requirements are needed for supervision organizations, such as increase the transparency of supervision and more involvement of media supervision (Wang et al., 2018b). Also, an 
appropriate stimulation mechanism is needed to stimulate supervision organization to supervise the project quality on time and effectively. In addition, the supervision unit should improve supervision ability and reduce the supervision cost by means of the supervision technology innovation, such as the remote monitoring system and the security early warning system (Yang et al., 2018; Li et al., 2014). At the same time, the supervision unit can carry out regular personnel training, establish an assessment mechanism, and actively use information technology to improve the working ability and efficiency of the supervision personnel.

Third, for the project contractor, the project contractor shall improve the level and efficiency of safe construction and reduce the probability of accidents through construction technology innovation (Wang et al., 2018a). Also, safety training for construction personnel should be strengthened to enhance their safety awareness. As the direct manager of the project quality, the project contractors develop based on good project quality. They should enhance the understanding of project quality and regard the project quality as important competitiveness and social responsibility.

\section{Conclusions}

The project corruption represented by power rent-seeking has laid numerous potential accidents for safe construction. In particular, the rent-seeking behavior between the project contractor and the project supervision seriously threatens the interests of the public. It leads to the unbalanced allocation of resources and the waste of social resources. Therefore, for the lack of effective supervision of MIPs resulting in safety accidents, this paper comprehensively considered the psychological factors such as loss avoidance and cognitive bias of game players, and introduced the prospect theory to construct a tripartite evolutionary game model for the rent-seeking behavior supervision among the project owners, supervision units and project contractors. Also, this paper discussed the interaction mechanism of the tripartite game players and the main factors affecting the evolution of the system through system dynamics simulation.

The results showed that the stable state of the optimal strategy in the rent-seeking behavior supervision system of MIPs is related to the cognitive bias of the game players and is influenced by the level of regulation cost, the intensity of punishment and the size of accident losses. The main conclusions are as follows: First, the conditions for the rent-seeking behavior supervision system to achieve the ideal stable strategy set \{strict regulation, rejecting rent-seeking, normative construction\} are that the perceived value of the supervision unit to punishment is greater than the difference between the cost of rejecting rent-seeking and accepting rent-seeking, and the perceived value of the project contractor to punishment and accident loss is greater than the additional benefit of conducting non-normative construction. In short, the project owner's punishment for the rent-seeking behavior of the supervision unit and the project contractor and accident loss should be greater than their unproductive benefits. However, due to the existence of cognitive bias and value perception preference, the game players will underestimate the probability of punishment for violation and accident and the perceived value of loss, so that the system deviates from the ideal stable state. Second, the strategy choice of the supervision unit is more sensitive to the change of penalty, while the change of penalty has no significant effect on the project contractor's strategy. Third, the increase in regulation cost of refusing the rent-seeking behavior strategy and the decrease in regulation cost of accepting the rent-seeking behavior strategy will promote the supervision unit to choose the rentseeking strategy. With the reduction of supervision cost for choosing rent-seeking strategy, supervision units are more willing to choose active supervision. Finally, when the cost difference between normative construction and non-normative construction reaches a certain level, the willingness of the project contractor to choose normative construction will be reduced, and the larger the cost difference is, the fewer iterations are needed to reach the evolutionary stable equilibrium.

The system complexity and depth uncertainty of MIPs make the differences among the project owners, supervision units and project contractors in engineering cognition, capability, benefit, and risk preferences more obvious, and there are phenomena of strategy selection and dynamic adjustment based on subjective feelings and value judgment of objective facts. Therefore, this paper constructed the rent-seeking behavior supervision model of MIPs based on the prospect theory and evolutionary game theory. Then, the system dynamics model is used to simulate the influence of changes in variables and parameters on the evolution results of the game player's strategy selection, revealing the dynamic evolution mechanism for behavior decision-making of different subjects in the rent-seeking behavior supervision process. Despite the contributions of this study, several limitations are to be acknowledged. Simulation results may be closer to practice if the data related to the actual situation of MIPs are directly used. In that case, there may be higher requirements for the simulation design, which is an improvement that needs to be considered in future research.

\section{Funding}

This work was supported by the $<\mathrm{MOE}$ (Ministry of Education in China) Project of Humanities and Social Sciences> under Grant [number 19YJC630078]; <Fundamental Research Funds for the Central Universities> under Grant [number B200207012]; and <Youth Talents Teachers Scheme of Henan Province Universities> under Grant [number 2018GGJS080]. 


\section{Author contributions}

Huimin Li and Zhuofu Wang conceived the study. Chengyi Zhang and Ran Qiao adding findings to the manuscript and revising the work. Lelin Lv and Huimin Li were responsible for writing the first draft of the article, along with contributing to revising the manuscript.

\section{Disclosure statement}

Authors have no competing financial, professional, or personal interests from other parties related to this research study.

\section{References}

Aidt, T. S. (2016). Rent seeking and the economics of corruption. Constitutional Political Economy, 27(2), 142-157. https://doi.org/10.1007/s10602-016-9215-9

Asilian-Mahabadi, H., Khosravi, Y., Hassanzadeh-Rangi, N., Hajizadeh, E., \& Behzadan, A. H. (2018). A qualitative investigation of factors influencing unsafe work behaviors on construction projects. Work, 61(2), 281-293.

https://doi.org/10.3233/wor-182799

Barberis, N. C. (2013). Thirty years of prospect theory in economics: A review and assessment. Journal of Economic Perspectives, 27(1), 173-195. https://doi.org/10.1257/jep.27.1.173

Cao, G., \& Zhou, L. (2021). The optimal PPP model of emergency rescue service. Discrete Dynamics in Nature and Society, 2021, 8413786. https://doi.org/10.1155/2021/8413786

Chen, H., Feng, Q., \& Cao, J. (2014). Rent-seeking mechanism for safety supervision in the Chinese coal industry based on a tripartite game model. Energy Policy, 72(9), 140-145. https://doi.org/10.1016 /j.enpol.2014.04.017

Chen, H., Feng, Q., Zhu, D., Han, S., \& Long, R. (2016). Impact of rent-seeking on productivity in Chinese coal mine safety supervision: A simulation study. Energy Policy, 93(6), 315-329. https://doi.org/10.1016/j.enpol.2016.02.054

Chen, M., Tian, S., \& Chen, P. (2015). Evolutionary game analysis between service of public library and the investment of government. In the 7th International Conference on Intelligent Human-Machine Systems and Cybernetics, Hangzhou, China. https://doi.org/10.1109/IHMSC.2015.174

Cheng, L., \& Yu, T. (2018). Nash equilibrium-based asymptotic stability analysis of multi-group asymmetric evolutionary games in typical scenario of electricity market. IEEE Access, 6, 32064-32086. https://doi.org/10.1109/access.2018.2842469

Deptula, P., Bell, Z. I., Zegers, F. M., Licitra, R. A., \& Dixon, W. E. (2018). Single agent indirect herding via approximate dynamic programming. In the 57th IEEE Conference on Decision and Control, Miami Beach, FL., USA. https://doi.org/10.1109/CDC.2018.8619066

Feng, Q., Shi, X., \& Zhang, J. (2019). Influence of rent-seeking on safety supervision in Chinese construction: Based on a simulation technology. Technological Forecasting and Social Change, 138(1), 1-9.

https://doi.org/10.1016/j.techfore.2018.10.016

Flyvbjerg, B. (2014). What you should know about megaprojects and why: An overview. Project Management Journal, 45(2), 6-19. https://doi.org/10.1002/pmj.21409
Flyvbjerg, B., \& Turner, J. R. (2018). Do classics exist in megaproject management? International Journal of Project Management, 36(2), 334-341.

https://doi.org/10.1016/j.ijproman.2017.07.006

Friedman, D. (1998). On economic application of evolutionary game theory. Journal of Evolutionary Economics, 8(1), 15-43. https://doi.org/10.1007/s001910050054

Gong, S., Gao, X., Li, Z., \& Chen, L. (2021). Developing a dynamic supervision mechanism to improve construction safety investment supervision efficiency in China: Theoretical simulation of evolutionary game process. International Journal of Environmental Research and Public Health, 18(7), 3594. https://doi.org/10.3390/ijerph18073594

Gu, S., Zhang, P., \& Yang, J. (2018). System dynamics model based on evolutionary game theory for quality supervision among construction stakeholders. Journal of Civil Engineering and Management, 24(4), 318-330.

https://doi.org/10.3846/jcem.2018.3068

He, H., \& Shan, B. (2021). Rent dissipation and administration of mining rent-seeking activities in resource-rich regions. Arabian Journal of Geosciences, 14(3), 171. https://doi.org/10.1007/s12517-021-06480-1

Hu, Y. C., \& Shen, Q. P. (2001). A system dynamics study of the development of the housing industry in Hong Kong. Systems Engineering Theory and Practice, 21(7), 32-37. https://10.3321/j.issn:1000-6788.2001.07.006

Ibarrondo-Davila, M. P., Lopez-Alonso, M., \& Rubio-Gamez, M. C. (2015). Managerial accounting for safety management. The case of a Spanish construction company. Safety Science, 79(11), 116-125. https://doi.org/10.1016/j.ssci.2015.05.014

Kahneman, D., \& Tversky, A. (1979). Prospect theory: An analysis of decision under risk. Econometrica, 47(2), 263-291. https://doi.org/10.2307/1914185

Kim, Y. A., Ryoo, B. Y., Kim, Y. S., \& Huh, W. C. (2013). Major accident factors for effective safety management of highway construction projects. Journal of Civil Engineering and Management, 139(6), 628-640.

https://doi.org/10.1061/(ASCE)CO.1943-7862.0000640

Lai, Y., \& Li, Y. (2013). The research on theory and applications of evolutionary game dynamics. In the International Conference on Information Engineering for Mechanics and Materials, Hangzhou, China.

https://doi.org/10.4028/www.scientific.net/AMM.422.309

Li, X. L. (2017). Evolution game analysis of public-private partnership projects regulatory with consideration of reputation. Journal of Systems Engineering, 32(2), 199-206. https://doi.org/10.13383/j.cnki.jse.2017.02.006

Li, T. H. Y., Ng, S. T., \& Skitmore, M. (2013). Evaluating stakeholder satisfaction during public participation in major infrastructure and construction projects: A fuzzy approach. Automation in Construction, 29(1), 123-135. https://doi.org/10.1016/j.autcon.2012.09.007

Li, Z., Tan, D. B., Zhang, S., Wang, R. P., \& Wang, X. B. (2014). Design and development of management information system for water project construction. Journal of Yangtze River Scientific Research Institute, 31(1), 66-71. https://doi.org/1001-5485(2014)31:1<66:SLGCJS>2.0.TX;2-1

Licitra, R. A., Bell, Z. I., \& Dixon, W. E. (2019). Single-agent indirect herding of multiple targets with uncertain dynamics. IEEE Transactions on Robotics, 35(4), 847-860.

https://doi.org/10.1109/tro.2019.2911799 
Liu, K., Liu, Y., Zhou, H., Kou, Y., Ji, Q., \& Li, D. (2021). Evolutionary game and numerical simulation of participants' collaborative behavior in integrated project delivery project. Alexandria Engineering Journal, 60(1), 373-385.

https://doi.org/10.1016/j.aej.2020.08.038

Liu, L., Zhao, Q., \& Bi, Y. (2020). Why rent-seeking behavior may exist in Chinese mining safety production inspection system and how to alleviate it: A tripartite game analysis. Resources Policy, 69(12), 101841.

https://doi.org/10.1016/j.resourpol.2020.101841

Liu, P., Jin, F., Zhang, X., Su, Y., \& Wang, M. (2011). Research on the multi-attribute decision-making under risk with interval probability based on prospect theory and the uncertain linguistic variables. Knowledge-Based Systems, 24(4), 554-561. https://doi.org/10.1016/j.knosys. 2011.01.010

Liu, Z., Sui, Y., Jin, Z., \& Yang, X. (2018). Evolution of major infrastructure projects social responsibility: From a global perspective. Journal of Systems and Management, 27(1), 101-108. https://doi.org/10.3969/j.issn.1005-2542.2018.01.013

Ma, T., Ding, J., Wang, Z., \& Skibniewski, M. J. (2020). Governing government-project owner relationships in water megaprojects: a concession game analysis on allocation of control rights. Water Resources Management, 34(13), 40034018. https://doi.org/10.1007/s11269-020-02627-Z

Mei, T. T., Wang, Q. K., Xiao, Y. P., \& Yang, M. (2017). Rent-seeking behavior of BIM-and IPD-based construction project in China. Engineering Construction and Architectural Management, 24(3), 514-536. https://doi.org/10.1108/ecam-11-2015-0178

Shen, H., Peng, Y., \& Guo, C. (2018). Analysis of the evolution game of construction and demolition waste recycling behavior based on prospect theory under environmental regulation. International Journal of Environmental Research and Public Health, 15(7), 1518. https://doi.org/10.3390/ijerph15071518

Si, T. M., \& Zhu, Y. (2008). Dynamic business analysis methods: systems thinking and modeling of complex worlds. Tsinghua University Press.

Taylor, P. D., \& Jonker, L. B. (1978). Evolutionarily stable strategies and game dynamics. Mathematical Biosciences, 40(1-2), 145-156. https://doi.org/10.1016/0025-5564(78)90077-9

Trepel, C., Fox, C. R., \& Poldrack, R. A. (2005). Prospect theory on the brain? Toward a cognitive neuroscience of decision under risk. Cognitive Brain Research, 23(1), 34-50.

https://doi.org/10.1016/j.cogbrainres.2005.01.016

Wang, C., Lee, Y. L., Yap, J., \& Abdul-Rahman, H. (2018a). Capabilities-based forecasting model for innovation development in small-and medium construction firms (SMCFS). Journal of Civil Engineering and Management, 24(3), 167-182.

https://doi.org/10.3846/jcem.2018.1626

Wang, G., Xue, Y., Skibniewski, M., Song, J. L. \& Lu, H. (2018b). Analysis of private investors conduct strategies by governments supervising public-private partnership projects in the new media era. Sustainability, 10(12), 4723.

https://doi.org/10.3390/su10124723

Wang, Y., Ding, H., \& Xiao, Y. (2014). Game analysis on rentseeking behavior of three participants in overseas engineering project. In the 7th International Joint Conference on Computational Sciences and Optimization, Beijing, China.

https://doi.org/10.1109/CSO.2014.24

Wen, S., Wu, G., \& Miao, Y. (2014). Collusion between supervision unit and contractor in construction project based on evolutionary game theory. Open Cybernetics and Systemics Journal, 8(1), 877-883. https://doi.org/10.2174/1874110X01408010877
Wu, C. L., \& Liu, C. C. (2013). An equilibrium analysis of the rent-seeking contests in infrastructure construction. In the International Conference on Mechatronics and Control Engineering, Guangzhou, China.

https://doi.org/10.4028/www.scientific.net/AMM.278-280.2313

Wu, D. D., Xie, K., Hua, L., Shi, Z., \& Olson, D. L. (2010). Modeling technological innovation risks of an entrepreneurial team using system dynamics: An agent-based perspective. Technological Forecasting and Social Change, 77(6), 857-869. https://doi.org/10.1016/j.techfore.2010.01.015

Xin, X. (2019). Research on safety regulation of chemical enterprise under third-party mechanism: An evolutionary approach. Symmetry, 11(8), 1057. https://doi.org/10.33 90/sym11081057

Xu, S., Zhou, Z., \& Liu, K. (2020). Multi-evolutionary game research on heavy metal pollution control in soil: Based on a third-party perspective. Sustainability, 12(13), 5306.

https://doi.org/10.3390/su12135306

Xu, Y. L., \& Zhao, C. G. (2009). Design of incentive mechanism and game analysis for project managers. In the IEEE 16th International Conference on Industrial Engineering and Engineering Management, Beijing, China.

https://doi.org/10.1109/ICIEEM.2009.5344558

Yang, Z., Wang, Y., \& Sun, C. (2018). Emerging information technology acceptance model for the development of smart construction system. Journal of Civil Engineering and Management, 24(6-8), 457-468.

https://doi.org/10.3846/jcem.2018.5186

Yuan, H. (2017). Achieving sustainability in railway projects: major stakeholder concerns. Project Management Journal, 48(5), 115-132. https://doi.org/10.1177/875697281704800508

Zhang, H., Ji, X., \& Wu, A. (2018). Analysis on the characteristics of ordinary and more serious accidents in building projects in China from 2005 to 2016. In the 3rd International Conference on Civil Engineering and Materials Science, Chengdu, China. https://doi.org/10.1051/matecconf/201820602012

Zhang, W., Zhu, S., Zhang, X., \& Zhao, T. (2020). Identification of critical causes of construction accidents in China using a model based on system thinking and case analysis. Safety Science, 121(1), 606-618. https://doi.org/10.1016/j.ssci.2019.04.038

Zhao, Z. Y., Zuo, J., \& Zillante, G. (2017). Transformation of water resource management: a case study of the South-to-North Water Diversion project. Journal of Cleaner Production, 163(10), 136-145. https://doi.org/10.1016/j.jclepro.2015.08.066 